Supporting Information belonging to the paper:

\title{
Octasubstituted metal-free phthalocyanine as core of phosphorus dendrimers: a probe for the properties of the internal structure \\ Julien Leclaire, ${ }^{a}$ Rodolphe Dagiral, ${ }^{a}$ Suzanne Fery-Forgues, ${ }^{b}$ Yannick Coppel, ${ }^{a}$ Bruno \\ Donnadieu, ${ }^{a}$ Anne-Marie Caminade* ${ }^{\text {a }}$ Jean-Pierre Majoral ${ }^{*}$ a \\ ${ }^{a}$ Laboratoire de Chimie de Coordination CNRS, 205 route de Narbonne, 31077 Toulouse Cedex 4, France \\ ${ }^{b}$ Laboratoire IMRCP, 118 route de Narbonne, 31062 Toulouse cedex 4, France.
}

\section{Experimental section}

\section{General}

All manipulations were carried out with standard high vacuum and dry-argon techniques. The solvents were freshly dried and distilled (THF and ether over sodium/benzophenone, pentane and $\mathrm{CH}_{2} \mathrm{Cl}_{2}$ over phosphorus pentoxide, toluene over sodium). Classical ${ }^{1} \mathrm{H},{ }^{13} \mathrm{C},{ }^{31} \mathrm{P}$ NMR spectra were recorded with Bruker AC 200, AC 250, DPX 300 or AMX 400 spectrometers. References for NMR chemical shifts are $85 \% \mathrm{H}_{3} \mathrm{PO}_{4}$ for ${ }^{31} \mathrm{P} \mathrm{NMR}, \mathrm{SiMe}_{4}$ for ${ }^{1} \mathrm{H}$ and ${ }^{13} \mathrm{C}$ NMR. The attribution of ${ }^{13} \mathrm{C}$ NMR signals has been done using $J_{\text {mod, two }}$ dimensional $\mathrm{HMBC}$, and $\mathrm{HMQC}$, Broad Band or $\mathrm{CW}{ }^{31} \mathrm{P}$ decoupling experiments when necessary. The numbering used for NMR assignments is depicted below:

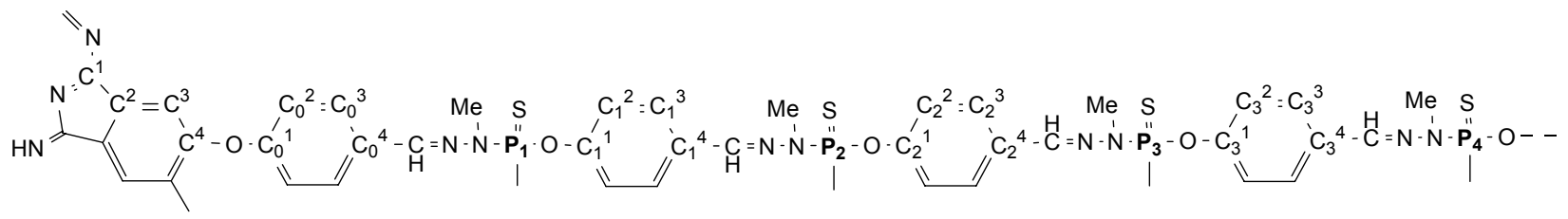

Synthesis of 3:

4,5-dichlorophthalonitrile $\mathbf{1}$ (2.000 g, $10.151 \mathrm{mmol})$, 4-hydroxybenzaldehyde sodium salt 2 (3.218 g, $22.332 \mathrm{mmol})$, and DMSO (60 mL) were introduced in a sealed Schlenk tube and heated for $48 \mathrm{~h}$ at $110^{\circ} \mathrm{C}$. After return to room temperature, cold water (200 mL) is added under stirring. The resulting heterogeneous solution is then centrifuged. The precipitate was recovered and washed again with water $(2 \times 80 \mathrm{~mL})$, then with methanol $(80 \mathrm{~mL})$, and dried 
under reduced pressure. 4.5-bis-(4-formylphenoxy)-phthalonitrile $\mathbf{3}$ is obtained as a maroon powder in $65 \%$ yield $(2.411 \mathrm{~g}, 6.545 \mathrm{mmol})$.

${ }^{1} \mathrm{H}$ NMR (DMSO-d $\left.)_{6}\right) 7.36\left(\mathrm{~d},{ }^{3} \mathrm{~J}_{\mathrm{HH}}=8.5 \mathrm{~Hz}, 4 \mathrm{H}, \mathrm{C}_{0}{ }^{2}-\mathrm{H}\right), 8.04\left(\mathrm{~d},{ }^{3} \mathrm{~J}_{\mathrm{HH}}=8.5 \mathrm{~Hz}, 4 \mathrm{H}, \mathrm{C}_{0}{ }^{3}-\right.$ H), $8.30\left(\mathrm{~s}, 2 \mathrm{H}, \mathrm{C}^{3}-\mathrm{H}\right), 10.05$ (s, 2H, CHO). ${ }^{13} \mathrm{C}\left\{{ }^{1} \mathrm{H}\right\}$ NMR (DMSO-d 6 ): $112.7\left(\mathrm{~s}, \mathrm{C}^{2}\right), 115.3$ $(\mathrm{s}, \mathrm{CN}), 118.2\left(\mathrm{~s}, \mathrm{C}_{0}^{2}\right), 127.7\left(\mathrm{~s}, \mathrm{C}^{3}\right), 132.1\left(\mathrm{~s}, \mathrm{C}_{0}{ }^{3}\right), 132.7\left(\mathrm{~s}, \mathrm{C}_{0}^{4}\right), 150.0\left(\mathrm{~s}, \mathrm{C}^{4}\right), 160.0(\mathrm{~s}$, $\mathrm{C}_{0}{ }^{1}$ ), 191.8 (s, CHO). I.R. (KBr): $1699 v_{\mathrm{CHO}}, 2229 v_{\mathrm{CN}}$. M.S. (E.I., $\left.70 \mathrm{eV}\right): m / z=368\left[\mathrm{M}^{+}\right]$. m.p.: 161-163 ${ }^{\circ}$ C. Anal. Calcd for $\mathrm{C}_{22} \mathrm{H}_{12} \mathrm{~N}_{2} \mathrm{O}_{4}$ (368.35): C, 71.74; H, 3.28; N, 7.61. Found: C, 72.01; H, 3.29; N, 7.58.

\section{Synthesis of $\mathbf{4 - \mathbf { G } _ { 0 }} \mathbf{0}^{\text {: }}$}

DBU $(0.132 \mathrm{~g}, 0.866 \mathrm{mmol})$ was added to a solution of $3(0.319 \mathrm{~g}, 0.866 \mathrm{mmol})$ in 1pentanol $(43 \mathrm{~mL})$. The resulting mixture was heated to reflux for $48 \mathrm{~h}$. After return to room temperature, the dark green precipitate was recovered and washed with methanol, then with acetone until the liquid phase became colorless. Phthalocyanine $\mathbf{4 - \mathbf { G } _ { \mathbf { 0 } }}$ was obtained as a poorly soluble green powder in $56 \%$ yield $(0.180 \mathrm{~g}, 0.122 \mathrm{mmol})$.

${ }^{1} \mathrm{H}$ NMR (DMSO-d (D) 7.27 (br s, $\left.16 \mathrm{H}, \mathrm{C}_{0}{ }^{2}-\mathrm{H}\right), 8.02$ (br s, $\left.24 \mathrm{H}, \mathrm{C}_{0}{ }^{3}-\mathrm{H}, \mathrm{C}^{3}-\mathrm{H}\right), 10.02$ (s, 8 H, CHO). I.R. (KBr): $1697 v_{\mathrm{CHO}}, 2930 v_{\mathrm{NH}}$. U.V. (DMF, $\left.\lambda_{\max }(\mathrm{nm})\right)$ : 346. 656. 672. M.S. (F.A.B., MNBA, DMF): $m / z=1474\left[\mathrm{M}^{+}\right]$. Anal. Calcd for $\mathrm{C}_{88} \mathrm{H}_{50} \mathrm{~N}_{8} \mathrm{O}_{16}$ (1475.4): C, 71.64; H, 3.42; N, 7.60. Found: C, 72.19; H, 3.36; N, 7.65.

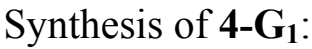

A solution of $0.286 \mathrm{M}$ dichlorothiophosphorhydrazide $(8.084 \mathrm{mmol})$ in chloroform $(28.3$ $\mathrm{mL})$ was added to phthalocyanine $\mathbf{4 - \mathbf { G } _ { 0 }} \mathbf{0}_{\mathbf{0}}(0.994 \mathrm{~g}, 0.674 \mathrm{mmol})$. The resulting suspension was stirred for $24 \mathrm{~h}$ at room temperature then filtered. The solution was recovered and evaporated to dryness. The resulting solid residue was washed with $15 \mathrm{~mL}$ of a THF/ether/pentane 1/1/1 
$\mathrm{v} / \mathrm{v} / \mathrm{v}$ mixture. Dendrimer $\mathbf{4}-\mathbf{G}_{\mathbf{1}}$ was isolated as a green powder in $37 \%$ yield $(0.694 \mathrm{~g}, 0.251$ mmol).

${ }^{31} \mathrm{P}\left\{{ }^{1} \mathrm{H}\right\}$ NMR $\left(\mathrm{CDCl}_{3}\right): 62.2\left(\mathrm{~s}, \mathrm{P}_{1}\right) .{ }^{1} \mathrm{H}$ NMR $\left(\mathrm{CDCl}_{3}\right): 3.44\left(\mathrm{~d},{ }^{3} \mathrm{~J}_{\mathrm{HP}}=13.3 \mathrm{~Hz}, 24 \mathrm{H}\right.$, $\mathrm{CH}_{3}$ ), 7.22 (br s, $\left.16 \mathrm{H}, \mathrm{C}_{0}{ }^{2}-\mathrm{H}\right), 7.65$ (br s, $\left.24 \mathrm{H}, \mathrm{C}_{0}{ }^{3}-\mathrm{H}, \mathrm{CH}=\mathrm{N}-\mathrm{N}\right), 8.3$ (br s, $\left.8 \mathrm{H}, \mathrm{C}^{3}-\mathrm{H}\right) .{ }^{13} \mathrm{C}$ $\left\{{ }^{1} \mathrm{H}\right\}$ NMR $\left(\mathrm{CDCl}_{3}\right): 31.9\left(\mathrm{~d},{ }^{2} \mathrm{~J}_{\mathrm{CP}}=12.9 \mathrm{~Hz}, \mathrm{CH}_{3}\right), 115.2\left(\mathrm{br} \mathrm{s}, \mathrm{C}^{2}\right), 118.0\left(\mathrm{br} \mathrm{s}, \mathrm{C}_{0}{ }^{2}, \mathrm{C}^{1}\right)$, $129.1\left(\mathrm{~s}, \mathrm{C}_{0}{ }^{3}\right), 129.8\left(\mathrm{~s}, \mathrm{C}^{3}\right), 131.8\left(\mathrm{~s}, \mathrm{C}_{0}{ }^{4}\right), 140.9\left(\mathrm{~d},{ }^{3} \mathrm{~J}_{\mathrm{CP}}=17.5 \mathrm{~Hz}, \mathrm{CH}=\mathrm{N}-\mathrm{N}\right), 149.7\left(\mathrm{~s}, \mathrm{C}^{4}\right)$, 158.6 (s, $\left.\mathrm{C}_{0}{ }^{1}\right)$. I.R. (KBr): $3291\left(v_{\mathrm{NH}}\right)$. Anal. Calcd for $\mathrm{C}_{96} \mathrm{H}_{74} \mathrm{Cl}_{16} \mathrm{~N}_{24} \mathrm{O}_{8} \mathrm{P}_{8} \mathrm{~S}_{8}$ (2763.4): C, 41.73; H, 2.70; N, 12.17. Found: C, 41.83; H, 2.68; N, 12.24 .

\section{Synthesis of $\mathbf{4 - \mathbf { G } ^ { \prime }} \mathbf{1}^{\text {: }}$}

Powdered 4-hydroxybenzaldehyde sodium salt $(0.695 \mathrm{~g}, 4.822 \mathrm{mmol})$ was added to a solution of dendrimer $4-\mathbf{G}_{\mathbf{1}}(0.694 \mathrm{~g}, 0.254 \mathrm{mmol})$ in THF $(20 \mathrm{~mL})$, then stirred at room temperature overnight. The resulting mixture was then centrifuged, and the solution was evaporated to dryness. The resulting residue was washed with $3 \times 15 \mathrm{~mL}$ of a ether/pentane $1 / 1$ v/v mixture, then dried under vacuum. Dendrimer $\mathbf{4}-\mathbf{G}_{\mathbf{1}} \mathbf{1}_{\text {was }}$ isolated as a green powder in 96 \% yield (1.000 g, $0.242 \mathrm{mmol})$.

${ }^{31} \mathrm{P}\left\{{ }^{1} \mathrm{H}\right\}$ NMR $\left(\mathrm{CDCl}_{3}\right): 61.1\left(\mathrm{~s}, \mathrm{P}_{1}\right) \cdot{ }^{1} \mathrm{H} \mathrm{NMR}\left(\mathrm{CDCl}_{3}\right): 3.35\left(\mathrm{~d},{ }^{3} \mathrm{~J}_{\mathrm{HP}}=10.5 \mathrm{~Hz}, 24 \mathrm{H}\right.$, $\left.\mathrm{CH}_{3}\right), 7.11\left(\mathrm{br} \mathrm{d},{ }^{2} \mathrm{~J}_{\mathrm{HH}}=6.0 \mathrm{~Hz}, 16 \mathrm{H}, \mathrm{C}_{0}{ }^{2}-\mathrm{H}\right), 7.32\left(\mathrm{~d},{ }^{3} \mathrm{~J}_{\mathrm{HH}}=8.3 \mathrm{~Hz}, 32 \mathrm{H}, \mathrm{C}_{1}{ }^{2}-\mathrm{H}\right), 7.64(\mathrm{br} \mathrm{s}$, $\left.24 \mathrm{H}, \mathrm{C}_{0}{ }^{3}-\mathrm{H}, \mathrm{CH}=\mathrm{N}-\mathrm{N}\right), 7.80\left(\mathrm{~d},{ }^{3} \mathrm{~J}_{\mathrm{HH}}=8.3 \mathrm{~Hz}, 32 \mathrm{H}, \mathrm{C}_{1}{ }^{3}\right), 8.0\left(\right.$ br s, $\left.8 \mathrm{H}, \mathrm{C}^{3}-\mathrm{H}\right), 9.87$ (br s, 16 $\mathrm{H}, \mathrm{CHO}) .{ }^{13} \mathrm{C}\left\{{ }^{1} \mathrm{H}\right\} \mathrm{NMR}\left(\mathrm{CDCl}_{3}\right): 32.8\left(\mathrm{~d},{ }^{2} \mathrm{~J}_{\mathrm{CP}}=12.6 \mathrm{~Hz}, \mathrm{CH}_{3}\right), 116.0$ (br s, $\left.\mathrm{C}^{2}\right), 117.7$ (br s, $\left.\mathrm{C}_{0}^{2}, \mathrm{C}^{1}\right), 122.0\left(\mathrm{~d},{ }^{3} \mathrm{~J}_{\mathrm{CP}}=4.6 \mathrm{~Hz}, \mathrm{C}_{1}^{2}\right), 128.7\left(\mathrm{~s}, \mathrm{C}_{0}^{3}\right), 129.9\left(\mathrm{~s}, \mathrm{C}^{3}\right), 131.4\left(\mathrm{br} \mathrm{s}, \mathrm{C}_{1}^{3}, \mathrm{C}_{0}^{4}\right)$, $133.6\left(\mathrm{~s}, \mathrm{C}_{1}{ }^{4}\right), 139.9\left(\mathrm{~d},{ }^{3} \mathrm{~J}_{\mathrm{CP}}=11.3 \mathrm{~Hz}, \mathrm{CH}=\mathrm{N}-\mathrm{N}\right), 150.1\left(\mathrm{~s}, \mathrm{C}^{4}\right), 155.1\left(\mathrm{~d},{ }^{2} \mathrm{~J}_{\mathrm{CP}}=7.8 \mathrm{~Hz}, \mathrm{C}_{1}{ }^{1}\right)$, $158.6\left(\mathrm{~s}, \mathrm{C}_{0}{ }^{1}\right), 190.8(\mathrm{~s}, \mathrm{CHO})$. I.R. (KBr): $1702 v_{\mathrm{CHO}}, 3290 v_{\mathrm{NH}}$. Anal. Calcd for $\mathrm{C}_{208} \mathrm{H}_{154} \mathrm{~N}_{24} \mathrm{O}_{40} \mathrm{P}_{8} \mathrm{~S}_{8}$ (4134.0): C, 60.43; H, 3.75; N, 8.13. Found: C, 61.02; H, 3.79; N, 8.09. 
General procedure for the synthesis of dendrimers $4-G_{n}$ and $4-G_{n}^{\prime}(n \geq 2)$

\author{
Dendrimers 4-Gn:
}

A solution of dichlorothiophosphorhydrazide $0.25 \mathrm{M}$ in chloroform was added to a solution of dendrimer $4-\mathbf{G}_{\mathbf{n}-\mathbf{1}}^{\prime}(\mathrm{n}=2-5)$ in THF (5 to $\left.10 \mathrm{~mL}\right)$. The resulting solution was stirred overnight at room temperature, then evaporated to dryness. The residue was washed with $3 \times 20 \mathrm{~mL}$ of ether/pentane $1 / 1 \mathrm{v} / \mathrm{v}$ mixture then dried under vacuum. Dendrimers $4-\mathbf{G}_{\mathbf{n}}$ were isolated as green powders.

\title{
Dendrimers 4-G' ${ }_{\mathbf{n}}$ :
}

Powdered 4-hydroxybenzaldehyde sodium salt (5\% excess) was added to a solution of dendrimer $4-\mathbf{G}_{\mathbf{n}}(500 \mathrm{mg})$ in THF (10 to $\left.20 \mathrm{~mL}\right)$, then stirred at room temperature overnight. The resulting mixture was then centrifuged, and the solution was evaporated to dryness. The resulting residue was washed with $10 \mathrm{~mL}$ of a THF/ether/pentane $1 / 2 / 2 \mathrm{v} / \mathrm{v} / \mathrm{v}$ mixture, then with $2 \times 10 \mathrm{~mL}$ of a ether/pentane $1 / 1 \mathrm{v} / \mathrm{v}$ mixture. The resulting solid was then dried under vacuum, affording $\mathbf{4}-\mathbf{G}_{\mathbf{n}}^{\prime}$ as a green powder.

4-G. $\mathbf{2} .84 \%$ yield. ${ }^{31} \mathrm{P}\left\{{ }^{1} \mathrm{H}\right\} \operatorname{NMR}\left(\mathrm{CDCl}_{3}\right): 61.1\left(\mathrm{~s}, \mathrm{P}_{1}\right), 63.0\left(\mathrm{~s}, \mathrm{P}_{2}\right) .{ }^{1} \mathrm{H}$ NMR $\left(\mathrm{CDCl}_{3}\right): 3.35$ (br d, $\left.{ }^{3} \mathrm{~J}_{\mathrm{HP}}=12.8 \mathrm{~Hz}, 72 \mathrm{H}, \mathrm{CH}_{3}\right)$, 7.0-7.4 (m, $\left.48 \mathrm{H}, \mathrm{C}_{0}^{2}-\mathrm{H}, \mathrm{C}_{1}^{2}-\mathrm{H}\right)$, 7.5-7.9 (m, $72 \mathrm{H}, \mathrm{C}_{0}^{3}-\mathrm{H}$, $\left.\mathrm{C}_{1}{ }^{3}-\mathrm{H}, \mathrm{CH}=\mathrm{N}-\mathrm{N}\right), 8.0$ (br s, $\left.8 \mathrm{H}, \mathrm{C}^{3}-\mathrm{H}\right) .{ }^{13} \mathrm{C}\left\{{ }^{1} \mathrm{H}\right\} \mathrm{NMR}\left(\mathrm{CDCl}_{3}\right): 31.8\left(\mathrm{~d},{ }^{2} \mathrm{~J}_{\mathrm{CP}}=12.3 \mathrm{~Hz}\right.$, $\left.\mathrm{CH}_{3}-\mathrm{N}-\mathrm{P}_{2}\right), 32.8\left(\mathrm{~d},{ }^{2} \mathrm{~J}_{\mathrm{CP}}=11.9 \mathrm{~Hz}, \mathrm{CH}_{3}-\mathrm{N}-\mathrm{P}_{1}\right), 117.8$ (br s, $\left.\mathrm{C}_{0}{ }^{2}, \mathrm{C}^{1}\right), 121.8\left(\mathrm{~s}, \mathrm{C}_{1}{ }^{2}\right), 128.1(\mathrm{~s}$, $\left.\mathrm{C}_{0}{ }^{3}\right), 128.6\left(\mathrm{~s}, \mathrm{C}_{1}{ }^{3}\right), 131.3\left(\mathrm{~s}, \mathrm{C}_{1}{ }^{4}\right), 131.5\left(\mathrm{~s}, \mathrm{C}_{0}{ }^{4}\right), 138.7\left(\mathrm{~d},{ }^{3} \mathrm{~J}_{\mathrm{CP}}=10.5 \mathrm{~Hz}, \mathrm{CH}=\mathrm{N}-\mathrm{N}-\mathrm{P}_{1}\right)$, $140.6\left(\mathrm{~d},{ }^{3} \mathrm{~J}_{\mathrm{CP}}=12.6 \mathrm{~Hz}, \mathrm{CH}=\mathrm{N}-\mathrm{N}-\mathrm{P}_{2}\right), 149.9\left(\mathrm{~s}, \mathrm{C}^{4}\right), 151.9\left(\mathrm{br} \mathrm{s}, \mathrm{C}_{1}{ }^{1}\right), 158.5\left(\mathrm{~s}, \mathrm{C}_{0}{ }^{1}\right)$. Anal. 
Calcd for $\mathrm{C}_{224} \mathrm{H}_{202} \mathrm{Cl}_{32} \mathrm{~N}_{56} \mathrm{O}_{24} \mathrm{P}_{24} \mathrm{~S}_{24}$ (6710): C, 40.10; H, 3.03; N, 11.69. Found: C, 40.01; H, $2.98 ; \mathrm{N}, 11.51$.

4-G' ${ }_{2 .} .98 \%$ yield. ${ }^{31} \mathrm{P}\left\{{ }^{1} \mathrm{H}\right\}$ NMR $\left(\mathrm{CDCl}_{3}\right): 60.9\left(\mathrm{~s}, \mathrm{P}_{2}\right), 62.6\left(\mathrm{~s}, \mathrm{P}_{1}\right) .{ }^{1} \mathrm{H}$ NMR $\left(\mathrm{CDCl}_{3}\right)$ : $3.31\left(\mathrm{br} \mathrm{d},{ }^{3} \mathrm{~J}_{\mathrm{HP}}=6.8 \mathrm{~Hz}, 72 \mathrm{H}, \mathrm{CH}_{3}\right), 6.8-7.4\left(\mathrm{~m}, 112 \mathrm{H}, \mathrm{C}_{0-2}{ }^{2}-\mathrm{H}\right), 7.4-8.2\left(\mathrm{~m}, 144 \mathrm{H}, \mathrm{C}_{0-2}{ }^{3}-\mathrm{H}\right.$, $\left.\mathrm{CH}=\mathrm{N}-\mathrm{N}, \mathrm{C}^{3}-\mathrm{H}\right), 9.82$ (br s, $\left.32 \mathrm{H}, \mathrm{CHO}\right) .{ }^{13} \mathrm{C}\left\{{ }^{1} \mathrm{H}\right\} \mathrm{NMR}\left(\mathrm{CDCl}_{3}\right): 33.3\left(\right.$ br m, $\left.\mathrm{CH}_{3}\right), 122.3$ (br s, $\left.\mathrm{C}_{1-2}{ }^{2}\right), 128.7\left(\mathrm{~s}, \mathrm{C}_{0-1}{ }^{3}\right), 131.8\left(\mathrm{~s}, \mathrm{C}_{2}{ }^{3}\right), 132.2\left(\mathrm{~s}, \mathrm{C}_{0-1}{ }^{4}\right), 134.0\left(\mathrm{~s}, \mathrm{C}_{2}{ }^{4}\right), 139.6-140.1(\mathrm{~m}$, $\mathrm{CH}=\mathrm{N}-\mathrm{N}), 152.0\left(\mathrm{~d},{ }^{2} \mathrm{~J}_{\mathrm{CP}}=7.0 \mathrm{~Hz}, \mathrm{C}_{1}{ }^{1}\right), 155.4\left(\mathrm{~d},{ }^{2} \mathrm{~J}_{\mathrm{CP}}=7.6 \mathrm{~Hz}, \mathrm{C}_{2}{ }^{1}\right), 159.0\left(\mathrm{~s}, \mathrm{C}_{0}{ }^{1}\right), 191.1(\mathrm{~s}$,

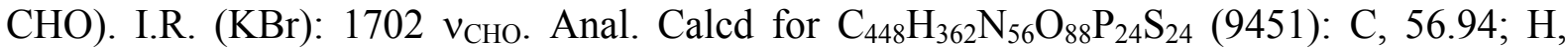
3.86; N, 8.30. Found: C, 56.56; H, 3.91; N, 8.27.

4-G. $84 \%$ yield. ${ }^{31} \mathrm{P}\left\{{ }^{1} \mathrm{H}\right\}$ NMR $\left(\mathrm{CDCl}_{3}\right): 62.0\left(\mathrm{~s}, \mathrm{P}_{2}\right), 62.4\left(\mathrm{~s}, \mathrm{P}_{1}\right), 63.0\left(\mathrm{~s}, \mathrm{P}_{3}\right) .{ }^{1} \mathrm{H}$ NMR $\left(\mathrm{CDCl}_{3}\right): 3.32\left(\mathrm{~d},{ }^{3} \mathrm{~J}_{\mathrm{HP}}=11.9 \mathrm{~Hz}, 168 \mathrm{H}, \mathrm{CH}_{3}\right), 6.8-7.4\left(\mathrm{~m}, 112 \mathrm{H}, \mathrm{C}_{0-2}{ }^{2}-\mathrm{H}\right)$, 7.4-8.0 (m, 176 $\left.\mathrm{H}, \mathrm{C}_{0-2}{ }^{3}-\mathrm{H}, \mathrm{CH}=\mathrm{N}-\mathrm{N}, \mathrm{C}^{3}-\mathrm{H}\right) .{ }^{13} \mathrm{C}\left\{{ }^{1} \mathrm{H}\right\} \mathrm{NMR}\left(\mathrm{CDCl}_{3}\right): 31.7\left(\mathrm{~d},{ }^{2} \mathrm{~J}_{\mathrm{CP}}=12.9 \mathrm{~Hz}, \mathrm{CH}_{3}-\mathrm{N}-\mathrm{P}_{3}\right)$, $32.9\left(\mathrm{~d},{ }^{2} \mathrm{~J}_{\mathrm{CP}}=11.1 \mathrm{~Hz}, \mathrm{CH}_{3}-\mathrm{N}-\mathrm{P}_{1-2}\right), 121.7\left(\mathrm{~s}, \mathrm{C}_{1-2}{ }^{2}\right), 128.2\left(\mathrm{~s}, \mathrm{C}_{0-1}{ }^{3}\right), 128.5\left(\mathrm{~s}, \mathrm{C}_{2}^{3}\right), 131.3(\mathrm{~s}$, $\left.\mathrm{C}_{0-2}{ }^{4}\right), 140.5\left(\mathrm{~d},{ }^{3} \mathrm{~J}_{\mathrm{CP}}=21.0 \mathrm{~Hz}, \mathrm{CH}=\mathrm{N}-\mathrm{N}\right), 151.6$ (br s, $\left.\mathrm{C}_{1-2}{ }^{1}\right)$. Anal. Calcd for $\mathrm{C}_{480} \mathrm{H}_{458} \mathrm{Cl}_{64} \mathrm{~N}_{120} \mathrm{O}_{56} \mathrm{P}_{56} \mathrm{~S}_{56}$ (14603): C, 39.48; H, 3.16; N, 11.51. Found: $\mathrm{C}, 39.92 ; \mathrm{H}, 3.06 ; \mathrm{N}$, 11.80

4-G' ${ }_{3 .} 81 \%$ yield. ${ }^{31} \mathrm{P}\left\{{ }^{1} \mathrm{H}\right\} \operatorname{NMR}\left(\mathrm{CDCl}_{3}\right): \delta=60.3\left(\mathrm{~s}, \mathrm{P}_{3}\right), 62.3\left(\mathrm{~s}, \mathrm{P}_{2}\right), 62.7\left(\mathrm{~s}, \mathrm{P}_{1}\right) .{ }^{1} \mathrm{H}$ $\operatorname{NMR}\left(\mathrm{CDCl}_{3}\right): \delta=3.32\left(\mathrm{br} \mathrm{d},{ }^{3} \mathrm{~J}_{\mathrm{HP}}=6.3 \mathrm{~Hz}, 168 \mathrm{H}, \mathrm{CH}_{3}\right), 6.8-7.4\left(\mathrm{~m}, 240 \mathrm{H}, \mathrm{C}_{0-3}{ }^{2}-\mathrm{H}\right), 7.4-$ $8.0\left(\mathrm{~m}, 304 \mathrm{H}, \mathrm{C}_{0-3}{ }^{3}-\mathrm{H}, \mathrm{CH}=\mathrm{N}-\mathrm{N}, \mathrm{C}^{3}-\mathrm{H}\right), 9.81$ (br s, $\left.64 \mathrm{H}, \mathrm{CHO}\right) .{ }^{13} \mathrm{C}\left\{{ }^{1} \mathrm{H}\right\} \mathrm{NMR}\left(\mathrm{CDCl}_{3}\right)$ : $33.0\left(\mathrm{~m}, \mathrm{CH}_{3}\right), 121.9\left(\right.$ br s, $\left.\mathrm{C}_{1-3}{ }^{2}\right), 128.3\left(\mathrm{~s}, \mathrm{C}_{0-2}{ }^{3}\right), 131.5\left(\mathrm{~s}, \mathrm{C}_{3}{ }^{3}\right), 131.8\left(\mathrm{~s}, \mathrm{C}_{0-1}{ }^{4}\right), 132.1(\mathrm{~s}$, $\left.\mathrm{C}_{2}{ }^{4}\right), 133.6\left(\mathrm{~s}, \mathrm{C}_{3}{ }^{4}\right), 139.0-140.4(\mathrm{~m}, \mathrm{CH}=\mathrm{N}-\mathrm{N}), 151.5$ (br s, $\left.\mathrm{C}_{1-2}{ }^{1}\right), 155.1$ (br s, $\left.\mathrm{C}_{3}{ }^{1}\right), 190.9$ (s, CHO). I.R. (KBr): $1702 v_{\text {CHO }}$. Anal. Calcd for $\mathrm{C}_{928} \mathrm{H}_{778} \mathrm{~N}_{120} \mathrm{O}_{184} \mathrm{P}_{56} \mathrm{~S}_{56}$ (20085): C, 55.50; H, 3.90; N, 8.37. Found: C, 55.26; H, 3.92; N, 8.21. 
4-G. $4.86 \%$ yield. ${ }^{31} \mathrm{P}\left\{{ }^{1} \mathrm{H}\right\} \operatorname{NMR}\left(\mathrm{CDCl}_{3}\right): \delta=61.9\left(\mathrm{~s}, \mathrm{P}_{3}\right), 62.2\left(\mathrm{~s}, \mathrm{P}_{2-1}\right), 63.2\left(\mathrm{~s}, \mathrm{P}_{4}\right) .{ }^{1} \mathrm{H}$ $\operatorname{NMR}\left(\mathrm{CDCl}_{3}\right): \delta=3.31\left(\mathrm{~d},{ }^{3} \mathrm{~J}_{\mathrm{HP}}=11.5 \mathrm{~Hz}, 360 \mathrm{H}, \mathrm{CH}_{3}\right), 6.8-7.4\left(\mathrm{~m}, 240 \mathrm{H}, \mathrm{C}_{0-3}{ }^{2}-\mathrm{H}\right), 7.4-8.0$ (m. $\left.368 \mathrm{H}, \mathrm{C}_{0-3}{ }^{3}-\mathrm{H}, \mathrm{CH}=\mathrm{N}-\mathrm{N}, \mathrm{C}^{3}-\mathrm{H}\right) .{ }^{13} \mathrm{C}\left\{{ }^{1} \mathrm{H}\right\} \mathrm{NMR}\left(\mathrm{CDCl}_{3}\right): 31.8\left(\mathrm{~d},{ }^{2} \mathrm{~J}_{\mathrm{CP}}=13.8 \mathrm{~Hz}, \mathrm{CH}_{3^{-}}\right.$ N-P $\left.\mathrm{P}_{4}\right), 33.9\left(\mathrm{~m}, \mathrm{CH}_{3}-\mathrm{N}-\mathrm{P}_{1-3}\right), 121.9\left(\mathrm{~s}, \mathrm{C}_{1-3}{ }^{2}\right), 128.3\left(\mathrm{~s}, \mathrm{C}_{0-2}{ }^{3}\right), 128.7\left(\mathrm{~s}, \mathrm{C}_{3}{ }^{3}\right), 131.5\left(\mathrm{~s}, \mathrm{C}_{3}{ }^{4}\right)$, $132.1\left(\mathrm{~s}, \mathrm{C}_{0-2}{ }^{4}\right), 138.7-139.5$ (m. $\left.\mathrm{CH}=\mathrm{N}-\mathrm{N}-\mathrm{P}_{1-3}\right), 140.7\left(\mathrm{~d},{ }^{3} \mathrm{~J}_{\mathrm{CP}}=18.6 \mathrm{~Hz}, \mathrm{CH}=\mathrm{N}-\mathrm{N}-\mathrm{P}_{4}\right), 151.4$ $\left(\mathrm{s}, \mathrm{C}_{1-2}{ }^{1}\right), 151.8\left(\mathrm{~s}, \mathrm{C}_{3}{ }^{1}\right)$. Anal. Calcd for $\mathrm{C}_{992} \mathrm{H}_{970} \mathrm{Cl}_{128} \mathrm{~N}_{248} \mathrm{O}_{120} \mathrm{P}_{120} \mathrm{~S}_{120}$ (30389): C, 39.21; H, 3.22; N, 11.43. Found: C, 39.36; H, 3.14; N, 11.41.

4-G' ${ }_{4} .88 \%$ yield. ${ }^{31} \mathrm{P}\left\{{ }^{1} \mathrm{H}\right\}$ NMR $\left(\mathrm{CDCl}_{3}\right): \delta=60.4\left(\mathrm{~s}, \mathrm{P}_{4}\right), 62.3\left(\mathrm{~s}, \mathrm{P}_{3}\right), 62.5\left(\mathrm{br} \mathrm{s}, \mathrm{P}_{2-1}\right) .{ }^{1} \mathrm{H}$ $\operatorname{NMR}\left(\mathrm{CDCl}_{3}\right): \delta=3.36\left(\mathrm{br} \mathrm{d},{ }^{3} \mathrm{~J}_{\mathrm{HP}}=6.3 \mathrm{~Hz}, 360 \mathrm{H}, \mathrm{CH}_{3}\right), 6.9-7.5\left(\mathrm{~m}, 496 \mathrm{H}, \mathrm{C}_{0-4}{ }^{2}-\mathrm{H}\right), 7.5-$ $8.0\left(\mathrm{~m}, 624 \mathrm{H}, \mathrm{C}_{0-4}{ }^{3}-\mathrm{H}, \mathrm{CH}=\mathrm{N}-\mathrm{N}, \mathrm{C}^{3}-\mathrm{H}\right), 9.88$ (br s, $\left.128 \mathrm{H}, \mathrm{CHO}\right) .{ }^{13} \mathrm{C}\left\{{ }^{1} \mathrm{H}\right\} \mathrm{NMR}\left(\mathrm{CDCl}_{3}\right)$ : $32.9\left(\mathrm{br} \mathrm{d},{ }^{2} \mathrm{~J}_{\mathrm{CP}}=13.1 \mathrm{~Hz}, \mathrm{CH}_{3}\right), 121.9\left(\mathrm{~s}, \mathrm{C}_{1-4}{ }^{2}\right), 128.3\left(\mathrm{~s}, \mathrm{C}_{0-3}{ }^{3}\right), 131.5\left(\mathrm{~s}, \mathrm{C}_{4}{ }^{3}\right), 131.8\left(\mathrm{~s}, \mathrm{C}_{3}{ }^{4}\right)$, 132.1 (br s, $\left.\mathrm{C}_{0-2}{ }^{4}\right), 133.6\left(\mathrm{~s}, \mathrm{C}_{4}{ }^{4}\right), 139.0-139.4\left(\mathrm{~m}, \mathrm{CH}=\mathrm{N}-\mathrm{N}-\mathrm{P}_{1-3}\right), 139.6\left(\mathrm{~d},{ }^{3} \mathrm{~J}_{\mathrm{CP}}=17.3 \mathrm{~Hz}\right.$, $\left.\mathrm{CH}=\mathrm{N}-\mathrm{N}-\mathrm{P}_{4}\right), 151.5$ (br s, $\left.\mathrm{C}_{1-3}{ }^{1}\right), 155.1\left(\mathrm{~d},{ }^{2} \mathrm{~J}_{\mathrm{CP}}=7.2 \mathrm{~Hz}, \mathrm{C}_{4}{ }^{1}\right), 190.8$ (s, CHO). I.R. (KBr): $1702 v_{\text {CHO }}$. Anal. Calcd for $\mathrm{C}_{1888} \mathrm{H}_{1610} \mathrm{~N}_{248} \mathrm{O}_{376} \mathrm{P}_{120} \mathrm{~S}_{120}$ (41354): C, 54.84; H, 3.92; N, 8.40. Found: C, 54.82; H, 3.78; N, 8.36.

4-G. $93 \%$ yield. ${ }^{31} \mathrm{P}\left\{{ }^{1} \mathrm{H}\right\} \operatorname{NMR}\left(\mathrm{CDCl}_{3}\right): \delta=61.4\left(\mathrm{~s}, \mathrm{P}_{4}\right), 62.3\left(\mathrm{~s}, \mathrm{P}_{0-3}\right), 63.6\left(\mathrm{~s}, \mathrm{P}_{5}\right) .{ }^{1} \mathrm{H}$ $\operatorname{NMR}\left(\mathrm{CDCl}_{3}\right): \delta=3.31\left(\right.$ br d, $\left.{ }^{3} \mathrm{~J}_{\mathrm{HP}}=11.5 \mathrm{~Hz}, 744 \mathrm{H}, \mathrm{CH}_{3}\right), 6.8-7.4\left(\mathrm{~m}, 496 \mathrm{H}, \mathrm{C}_{0-4}{ }^{2}-\mathrm{H}\right), 7.4-$ $8.0\left(\mathrm{~m}, 752 \mathrm{H}, \mathrm{C}_{0-4}{ }^{3}-\mathrm{H} . \mathrm{CH}=\mathrm{N}-\mathrm{N}-\mathrm{P}_{1-5}, \mathrm{C}^{3}-\mathrm{H}\right) .{ }^{13} \mathrm{C}\left\{{ }^{1} \mathrm{H}\right\}$ NMR $\left(\mathrm{CDCl}_{3}\right): 31.9\left(\mathrm{~d},{ }^{2} \mathrm{~J}_{\mathrm{CP}}=12.4\right.$ $\left.\mathrm{Hz}, \mathrm{CH}_{3}-\mathrm{N}-\mathrm{P}_{5}\right), 33.1\left(\mathrm{br} \mathrm{d},{ }^{2} \mathrm{~J}_{\mathrm{CP}}=13.0 \mathrm{~Hz}, \mathrm{CH}_{3}-\mathrm{N}-\mathrm{P}_{1-4}\right), 121.9\left(\mathrm{~s}, \mathrm{C}_{1-4}{ }^{2}\right), 128.3\left(\mathrm{~s}, \mathrm{C}_{0-3}{ }^{3}\right), 128.7$ $\left(\mathrm{s}, \mathrm{C}_{4}{ }^{3}\right), 131.5\left(\mathrm{~s}, \mathrm{C}_{4}{ }^{4}\right), 132.1\left(\mathrm{~s}, \mathrm{C}_{0-3}{ }^{4}\right), 139.1\left(\mathrm{br} \mathrm{d},{ }^{3} \mathrm{~J}_{\mathrm{CP}}=12.0 \mathrm{~Hz}, \mathrm{CH}=\mathrm{N}-\mathrm{N}-\mathrm{P}_{1-4}\right), 140.7(\mathrm{~d}$, $\left.{ }^{3} \mathrm{~J}_{\mathrm{CP}}=17.6 \mathrm{~Hz}, \mathrm{CH}=\mathrm{N}-\mathrm{N}-\mathrm{P}_{5}\right), 151.4\left(\mathrm{~d},{ }^{2} \mathrm{~J}_{\mathrm{CP}}=6.2 \mathrm{~Hz}, \mathrm{C}_{1-3}{ }^{1}\right), 151.8\left(\mathrm{~d},{ }^{2} \mathrm{~J}_{\mathrm{CP}}=5.0 \mathrm{~Hz}, \mathrm{C}_{4}{ }^{1}\right)$. Anal. Calcd for $\mathrm{C}_{2016} \mathrm{H}_{1994} \mathrm{Cl}_{256} \mathrm{~N}_{504} \mathrm{O}_{248} \mathrm{P}_{248} \mathrm{~S}_{248}$ (61961): C, 39.08; H, 3.24; N, 13.39. Found: C, 39.56; H, 3.22; N, 13.17 . 


\section{Diffusion NMR experiments}

The PGSE (pulse gradient spin-echo) NMR experiments were recorded on a Bruker Avance 500 spectrometer equipped with a $5 \mathrm{~mm}$ triple resonance inverse Z-gradient probe. All diffusion measurements were made using the BPLED ${ }^{1}$ pulse sequence with a diffusion time $\Delta$ of $200 \mathrm{~ms}$ and an eddy current delay $\left(\mathrm{T}_{\mathrm{e}}\right)$ of $5 \mathrm{~ms}$. The temperature was set at $298 \mathrm{~K}$ and sample spinning of $20 \mathrm{~Hz}$ was used. The recycle delay was adjusted to $30 \mathrm{~s}$ by measuring the $\mathrm{T}_{1}$ for all of the resonances of interest and setting it to $5 \times$ the $\mathrm{T}_{1}$ value of the slowest relaxing resonance. The shape of the gradients was sine-shaped with a length of $4.4 \mathrm{~ms}$ and the strength was varied in 10 increments (2-95\%) of the gradient ramp created by Bruker software DOSY. The strength of the gradient was calibrated by measuring the self diffusion of the residual $\mathrm{HDO}$ signal in a $100 \% \mathrm{D}_{2} \mathrm{O}$ sample at $298 \mathrm{~K}\left(1.9010^{-9} \mathrm{~m}^{2} . \mathrm{s}^{-1}\right)$. The diffusion coefficients were determined by linear least-squares fits to the Stejskal-Tanner plots ${ }^{2}$ using the Simfit algorithm of Bruker software package $T_{1} / T_{2}$.

\section{Fluorescence experiments}

Steady-state fluorescence work was performed on a Photon Technology International (PTI) Quanta Master 1 spectrofluorometer. All fluorescence spectra were corrected. The fluorescence quantum yields $(\Phi)$ were determined using the formula: $\Phi_{4-G{ }^{\prime}}=\left(A_{s} \times F_{4-G{ }^{\prime n}} \times\right.$ $\left.n_{4-\mathrm{G}_{\mathrm{n}}}{ }^{2} \times \Phi_{\mathrm{s}}\right) /\left(\mathrm{A}_{4-\mathrm{G}{ }_{\mathrm{n}}} \times \mathrm{F}_{\mathrm{S}} \times n_{\mathrm{s}}{ }^{2}\right)$ where $\mathrm{A}$ is absorbance at the excitation wavelength, $\mathrm{F}$ is the area under the fluorescence curve, and $n$ is the refractive index. Subscript $s$ refers to the standard. The latter was 3,3'-diethyloxatricarbocyanine iodide (DOTCI) in absolute ethanol $(\Phi=0.49)[21]$. All the samples and the standard were excited at $646 \mathrm{~nm}$, the absorbance being around 0.05 . Fluorescence decay was measured with the stroboscopic technique utilising a Strobe Master fluorescence lifetime spectrometer from PTI. The excitation source 
was a flash lamp filled with a mixture of nitrogen and helium (30/70). The excitation wavelength was $337 \mathrm{~nm}$. Data were collected over 200 channels with a time-base of $0.1 \mathrm{~ns}$ per channel. Analysis of fluorescence decay was performed using the multiexponential method software from PTI. All spectrophotometric measurements were conducted in a thermostatted cell at $20^{\circ} \mathrm{C}$. The measurements of quantum yields and lifetimes were carried out in solutions containing $\mathrm{HCl} 10^{-4} \mathrm{M}\left(1 / 1000 \mathrm{v} / \mathrm{v} \mathrm{H}_{2} \mathrm{O} / \mathrm{THF}\right)$ for the neutral form, and $\mathrm{NaOH} 6.76 \times 10^{-4} \mathrm{M}$ (3.4/100 v/v $\left.\mathrm{H}_{2} \mathrm{O} / \mathrm{THF}\right)$ for the dianionic form.

To measure the variation of the fluorescence spectrum in the presence of basis, aliquots of aqueous $\mathrm{NaOH} 2 \times 10^{-4} \mathrm{M}$ were successively added to a solution of dendrimers in THF containing $\mathrm{HCl} 10^{-4} \mathrm{M}$. After each addition, the solution was left to stand 5 minutes under mechanical stirring before measurement.

\section{$X$-Ray Structure Determination of $3\left(\mathrm{C}_{22} \mathrm{H}_{12} \mathrm{~N}_{2} \mathrm{O}_{4}, 0.5 \mathrm{THF}\right)$}

Measurement were performed at low temperature $\mathrm{T}=160(2) \mathrm{K}$, on a one circle STOE imaging Plate Detector X-Ray diffractometer system (Mo-radiation, $\lambda=0.71073 \AA$ ). A phi scan strategy was used for the data collection (with a scan width of $0.5^{\circ}$ in $\phi$ angles of $0^{\circ}$ to $250^{\circ}$ for 166 frames, $5 \mathrm{~min} /$ frame exposure time). Frames were integrated using the STOE software package X-RED. ${ }^{3}$ The integrated frames yielded a total of 7878 reflections collected at a maximum $2 \theta$ angle of $46.50^{\circ}\left(0.87 \AA\right.$ resolution, 2919 independent, $R_{\text {int }}=0.0488, R_{\text {sig }}=$ 0.0573 , completeness $=94.1 \%)$ and $1664(57.0 \%)$ reflections were found greater than $2 \sigma(\mathrm{I})$. The unit cell parameters were, $\mathrm{a}=7.9113(10) \AA, \mathrm{b}=10.7582(16) \AA, \mathrm{c}=13.113(2) \AA, \alpha=$ $83.553(18)^{\circ}, \beta=79.032(17)^{\circ}, \gamma=80.968(16)^{\circ}, V=1078.1(3) \AA^{3}, Z=2$, calculated density $\mathrm{D}_{\mathrm{c}}=1.246 \mathrm{Mg} / \mathrm{m}^{3}$. Absorption corrections were applied for all data using the DIFABS program. $^{4}$ The SIR92 software package ${ }^{5}$ and SHELXL $97^{6}$ were respectively used for phase 
determination and structure refinement. Direct methods of phase determination followed by some subsequent difference Fourier map led to an electron density map from which most of the non-hydrogen atoms were identified in the asymmetry unit of the unit cell. With subsequent isotropic refinement and Fourier difference synthesis, all of the non-hydrogen atoms were identified. Atomic coordinates, isotropic and anisotropic displacement parameters of all non-hydrogen atoms were refined by means of a full matrix least-squares procedure on $\mathrm{F}^{2} . \mathrm{H}$-atoms were included in the refinement in calculated positions, riding on the carbons atoms with an isotropic thermal parameter fixed $20 \%$ and $50 \%$ respectively higher, than $\mathrm{Csp}^{2}$ and $\mathrm{Csp}^{3}$ atoms to which there were attached. Concerning the methyl groups all torsions angles were refined. The refinement converged at $\mathrm{R} 1=0.0585, \mathrm{wR} 2=0.1555$ with intensity, $\mathrm{I}>2 \sigma(\mathrm{I})$, largest peak/hole in the final difference map were found to 0.815 and $-0.211 \mathrm{e} . \AA^{-3}$. All calculations were carried out using the WinGX 32 software package, ${ }^{7}$ drawing of molecule was achieved using the soft ORTEP $32,{ }^{8}$ with $50 \%$ probability displacement ellipsoids for non-hydrogen atoms.

\section{References}

(1) Wu, D.; Chen, A.; Johnson Jr., C.S. J. Magn. Reson. A 1995, 115, 260.

(2) Stejskal, E.O.; Tanner, J.E. J. Chem. Phys. 1965, 42, 288.

(3) Stoe, X-RED, Data Reduction for STADI4 and IPDS, Revision 1.08. Stoe \& Cie, Darmstadt, 1996, Germany.

(4) DIFABS.Walker, N.; Stuart, D. Acta Crystallogr., Sect A 1983, 39, 158.

(5) SIR92 - A program for crystal structure solution. Altomare, A.; Cascarano, G.; Giacovazzo C.; Guagliardi, A. J. Appl. Crystallogr. 1993, 26, 343. 
(6) SHELXTL Software Reference Manual, Version 6.10, Dec. $5^{\text {th }}, \mathbf{2 0 0 0}$, Bruker Analytical X-Ray System, Inc., Madison, WI.

(7) ORTEP3 for Windows. Farrugia, L.J. J. Appl. Crystallogr. 1997, 30, 565.

(8) WINGX - Version 1.64.05 Farrugia, L.J. J. Appl. Cryst. 1999, 32, 837.

\section{NMR Spectra}

\section{Important note:}

The NMR spectra have been done on several machines, which do not have the same zero value. It means that a single sample will have different chemical shifts, depending on the machine on which it was recorded. The difference may be of several ppm, especially for ${ }^{31} \mathrm{P}$ NMR. All the data given in the experimental section are taken from a single machine, in order to normalize the data. However, most of the spectra shown were obtained from another machine, thus the chemical shifts are slightly different. 


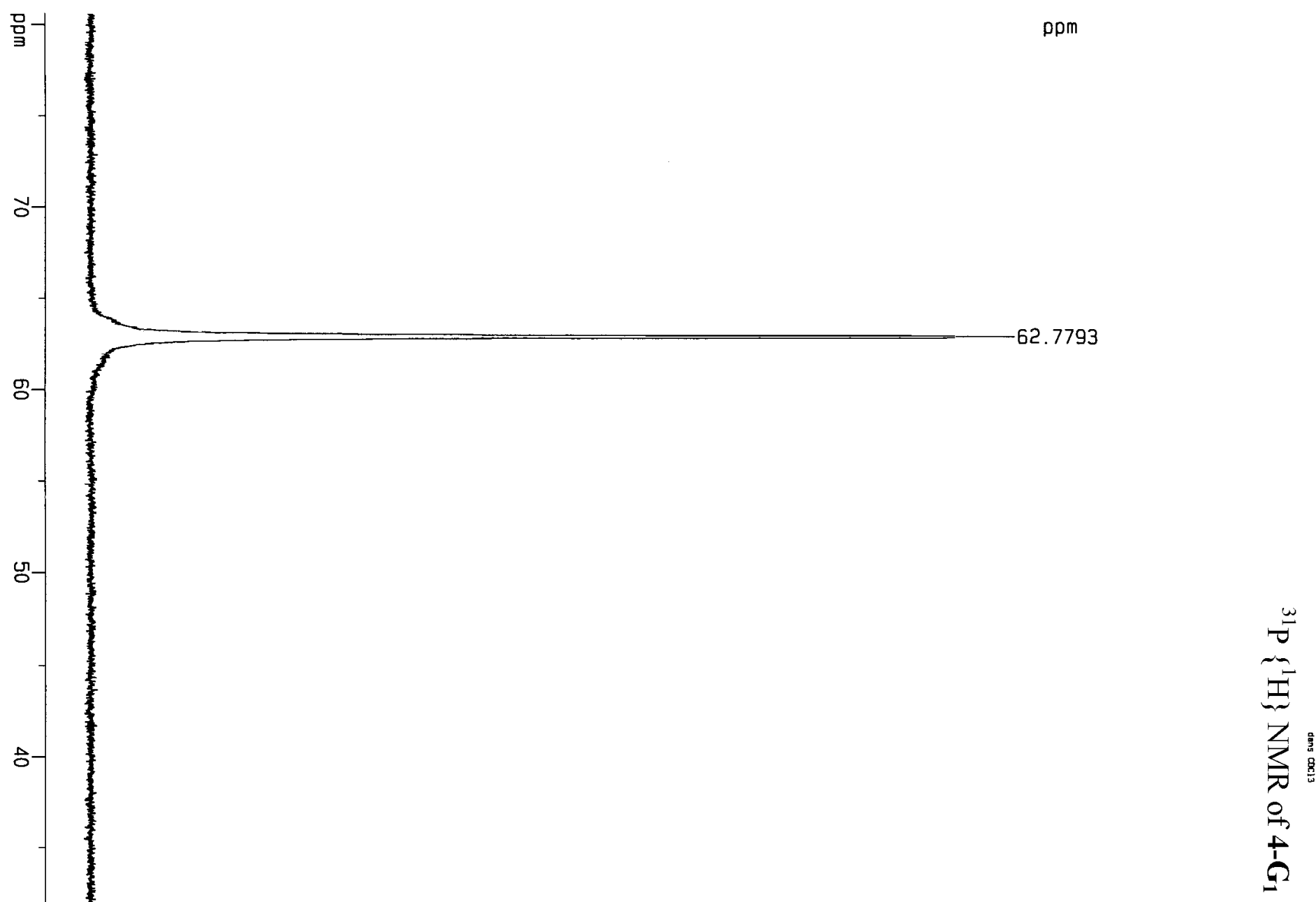

w

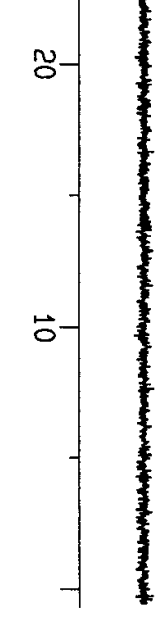

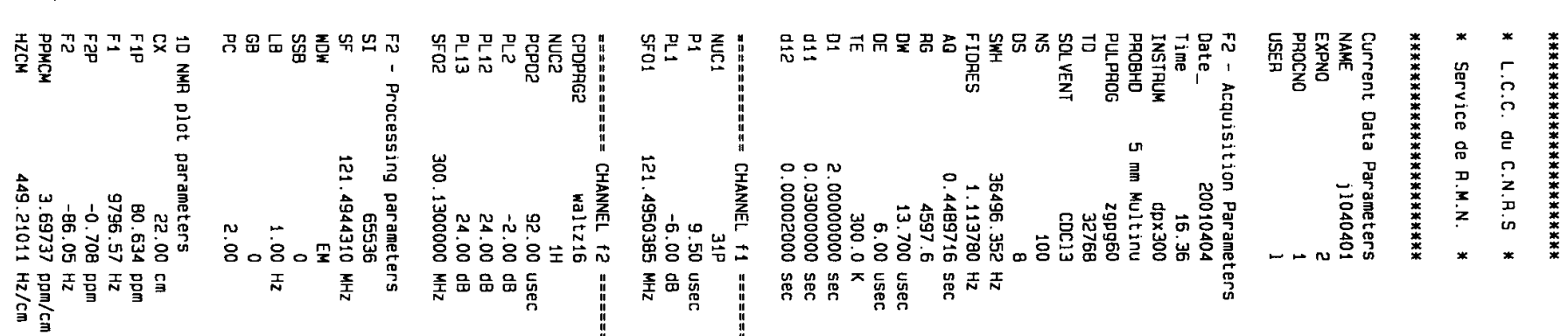



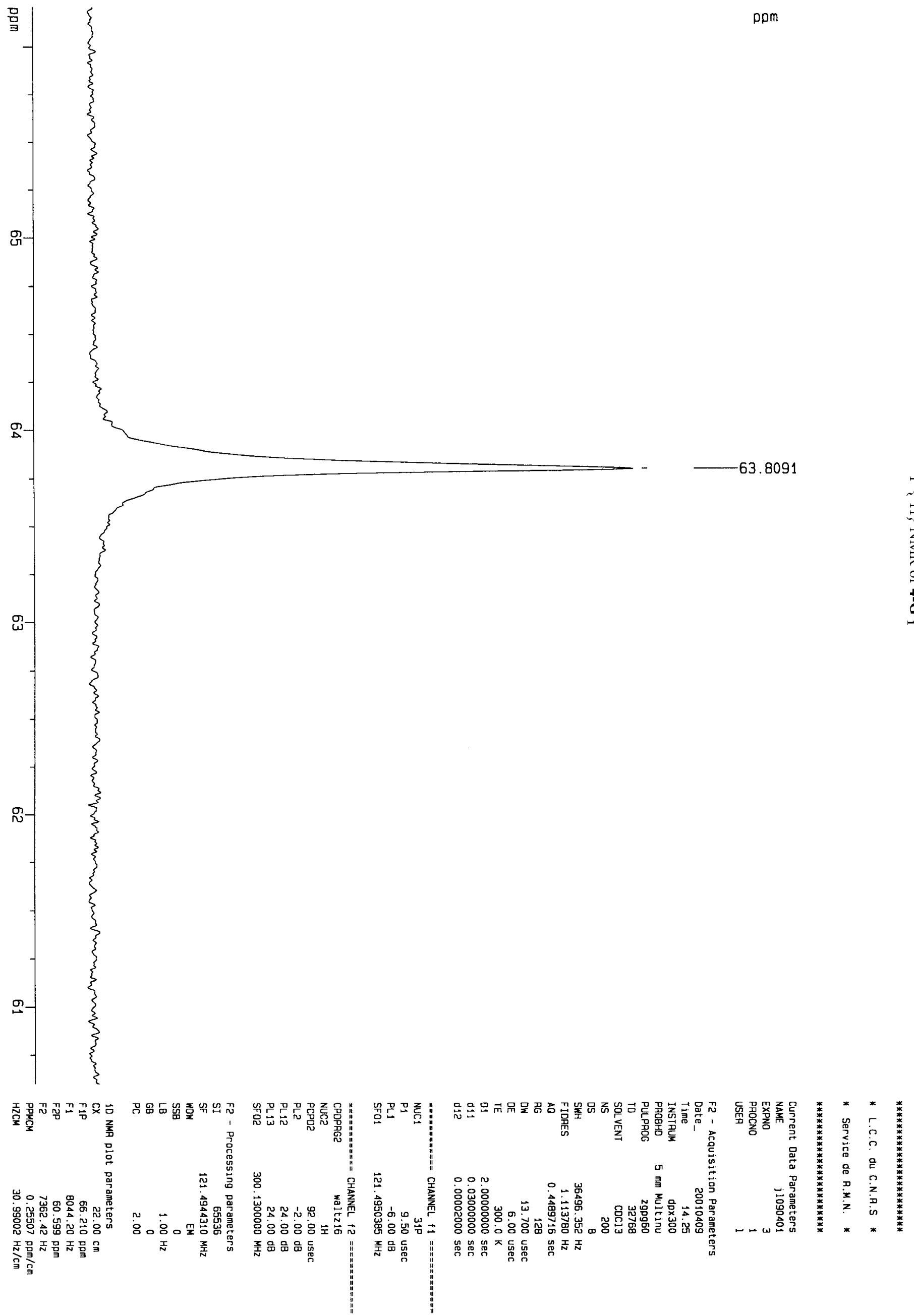


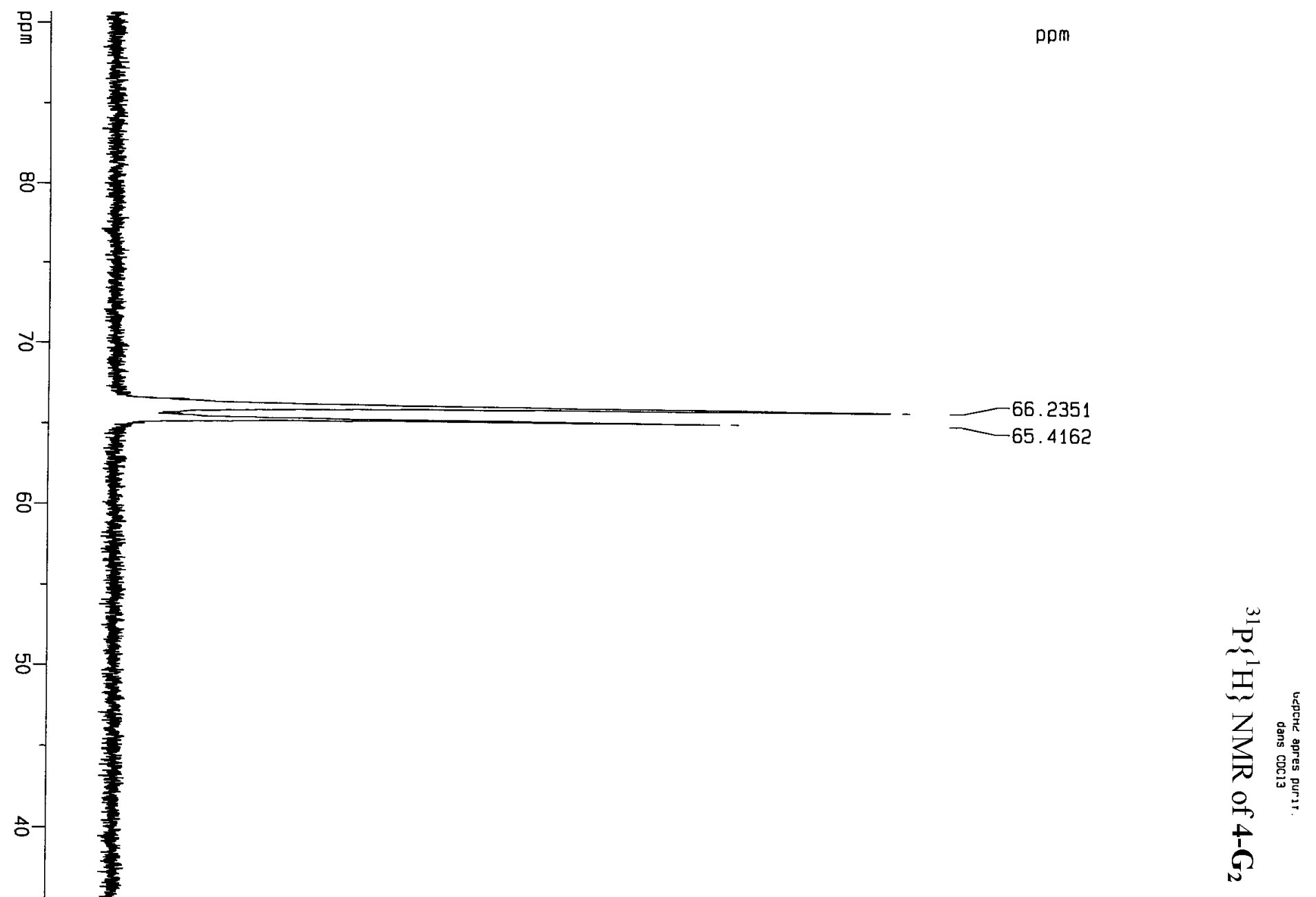

$w$

ㅇ-

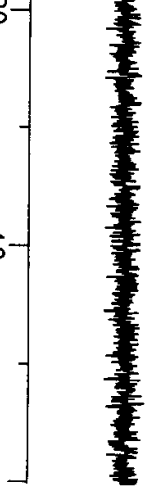

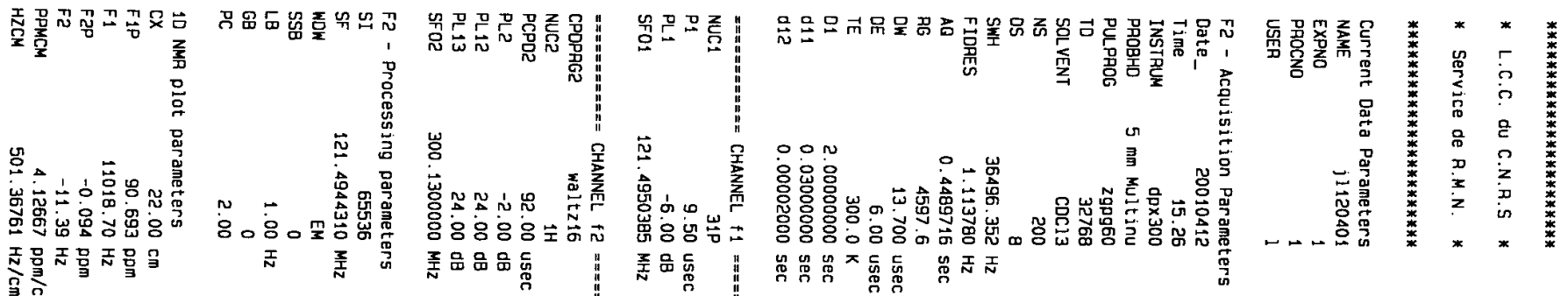




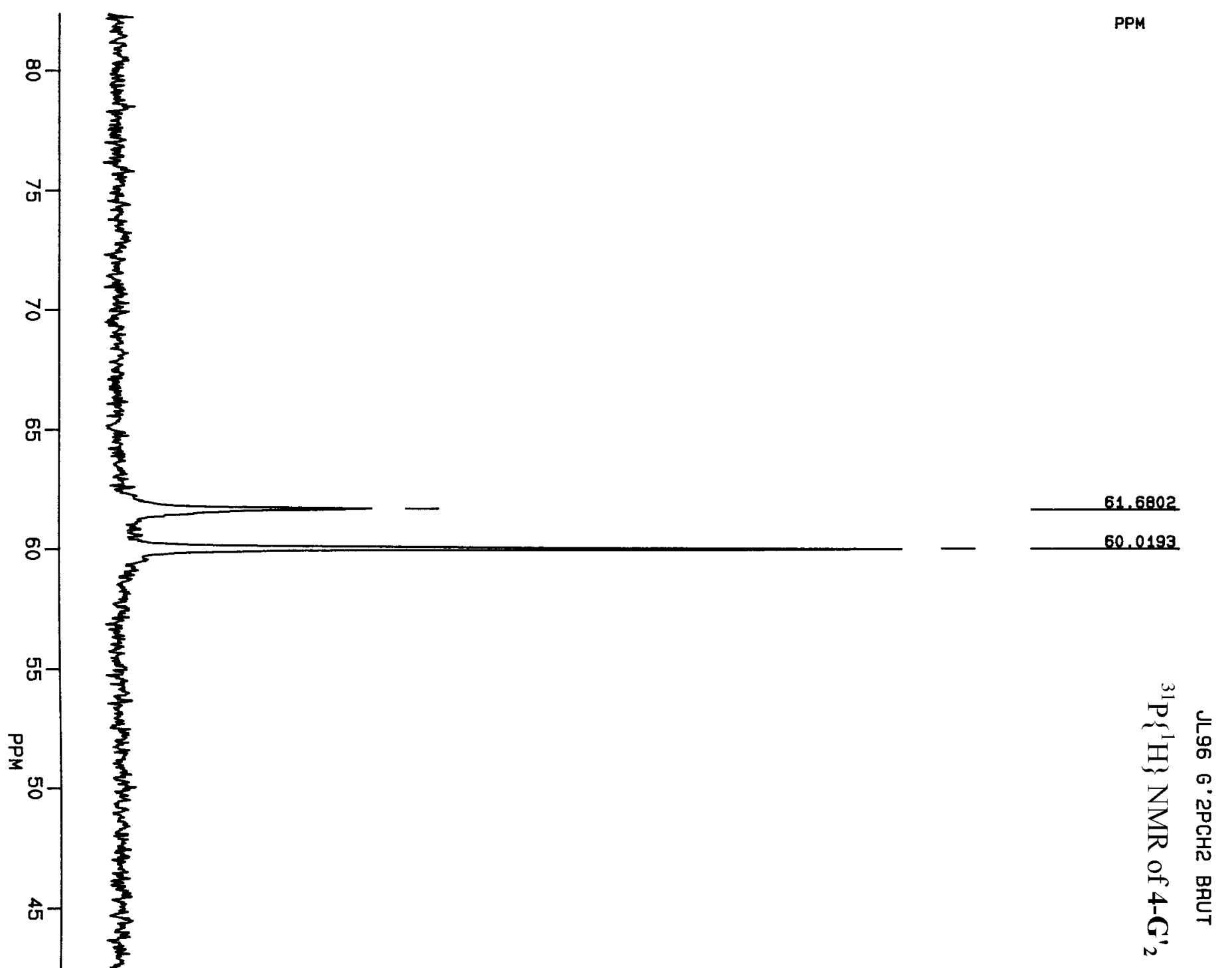

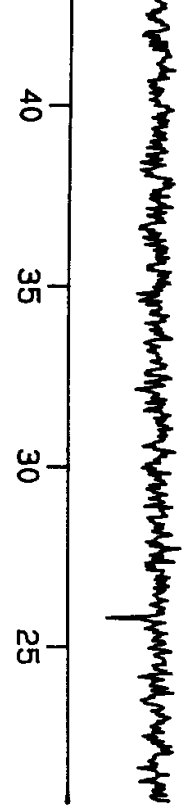

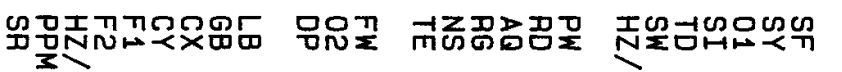

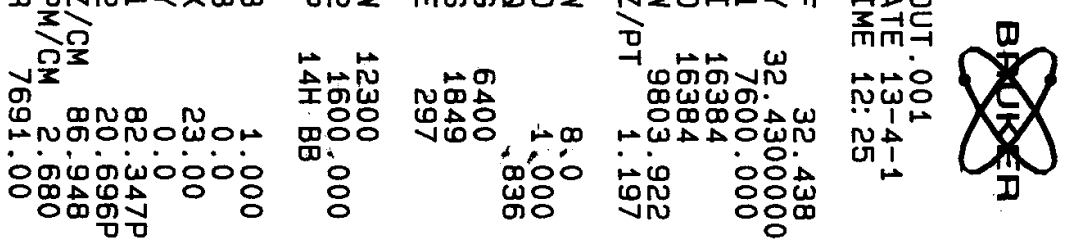




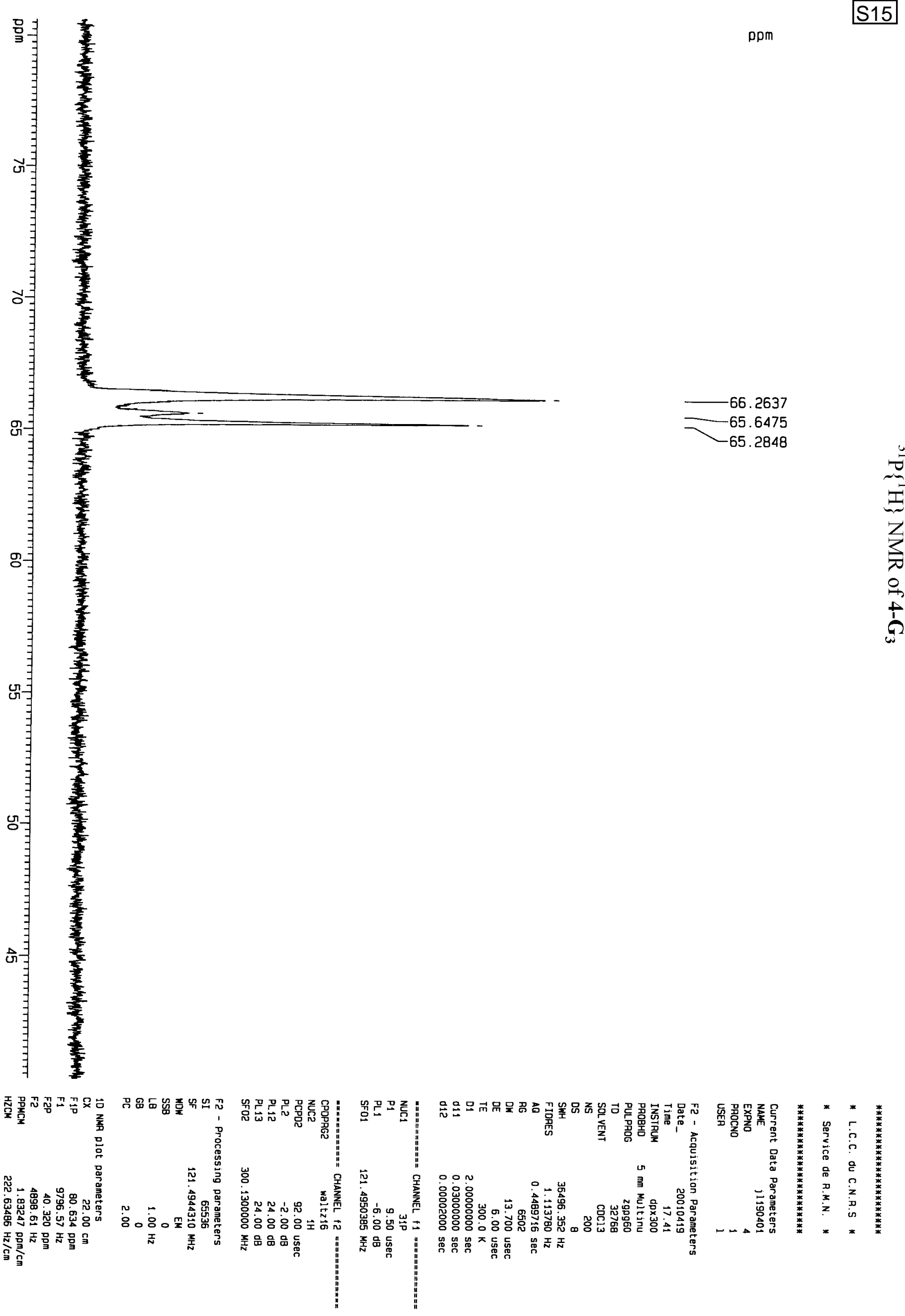




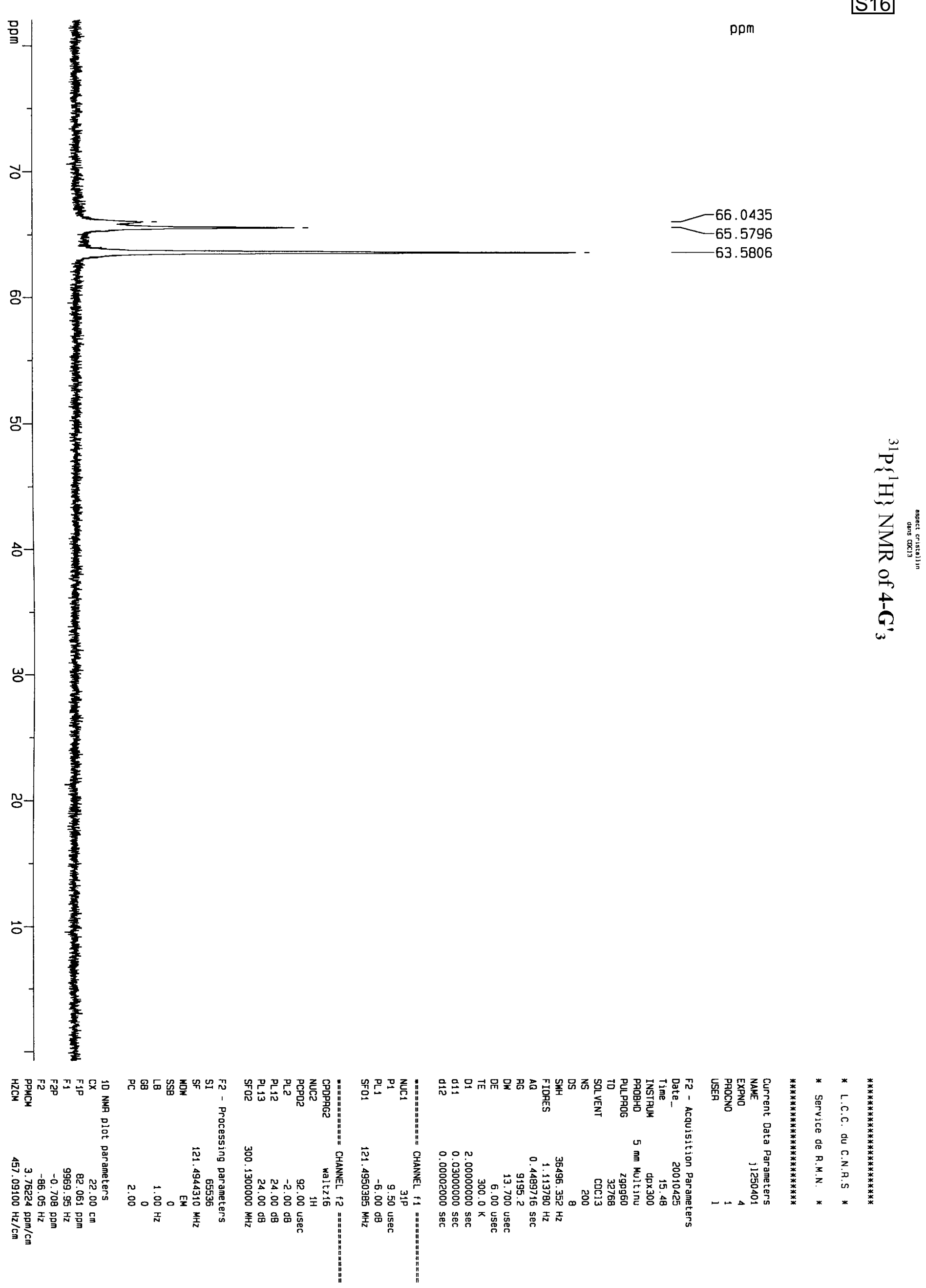




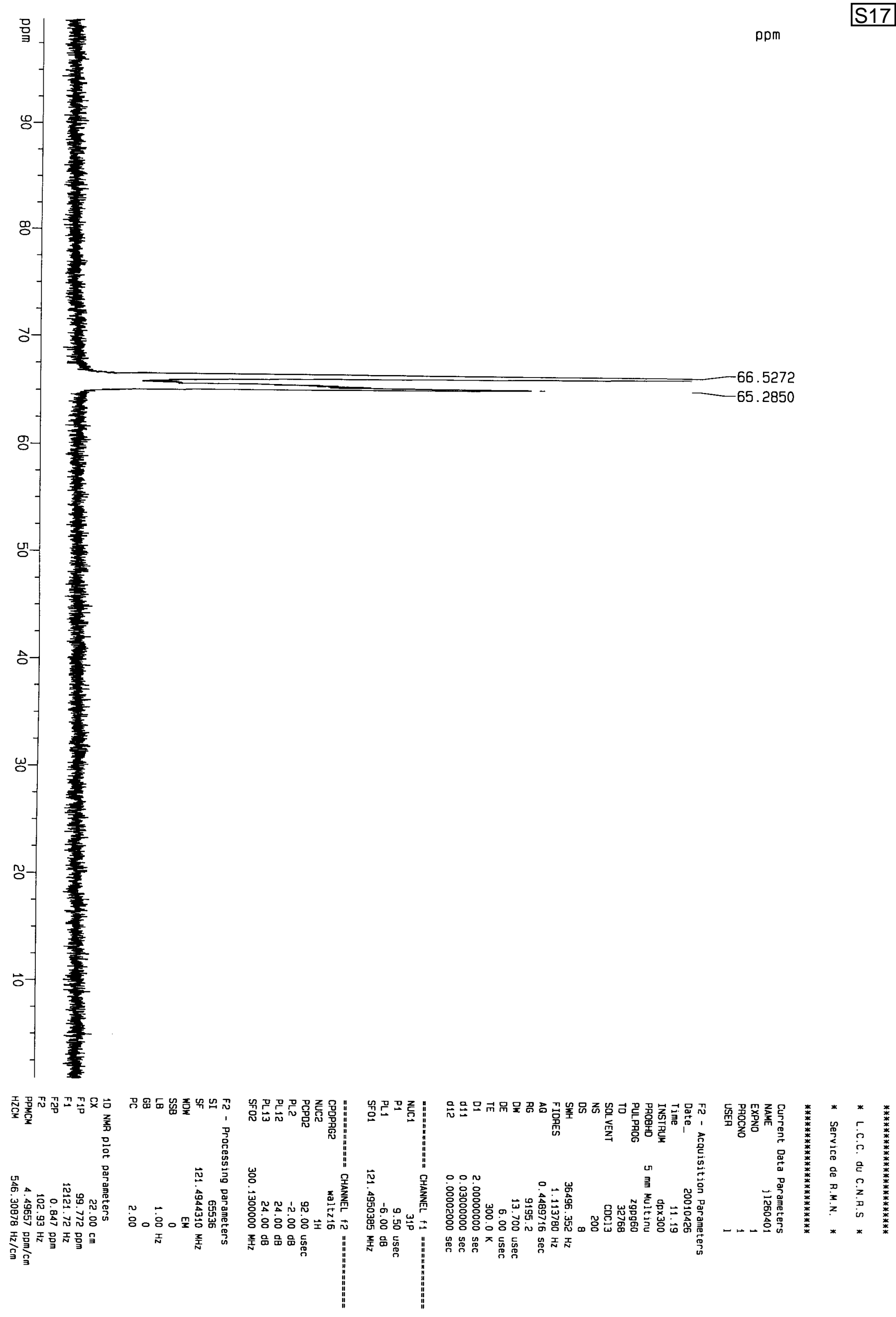



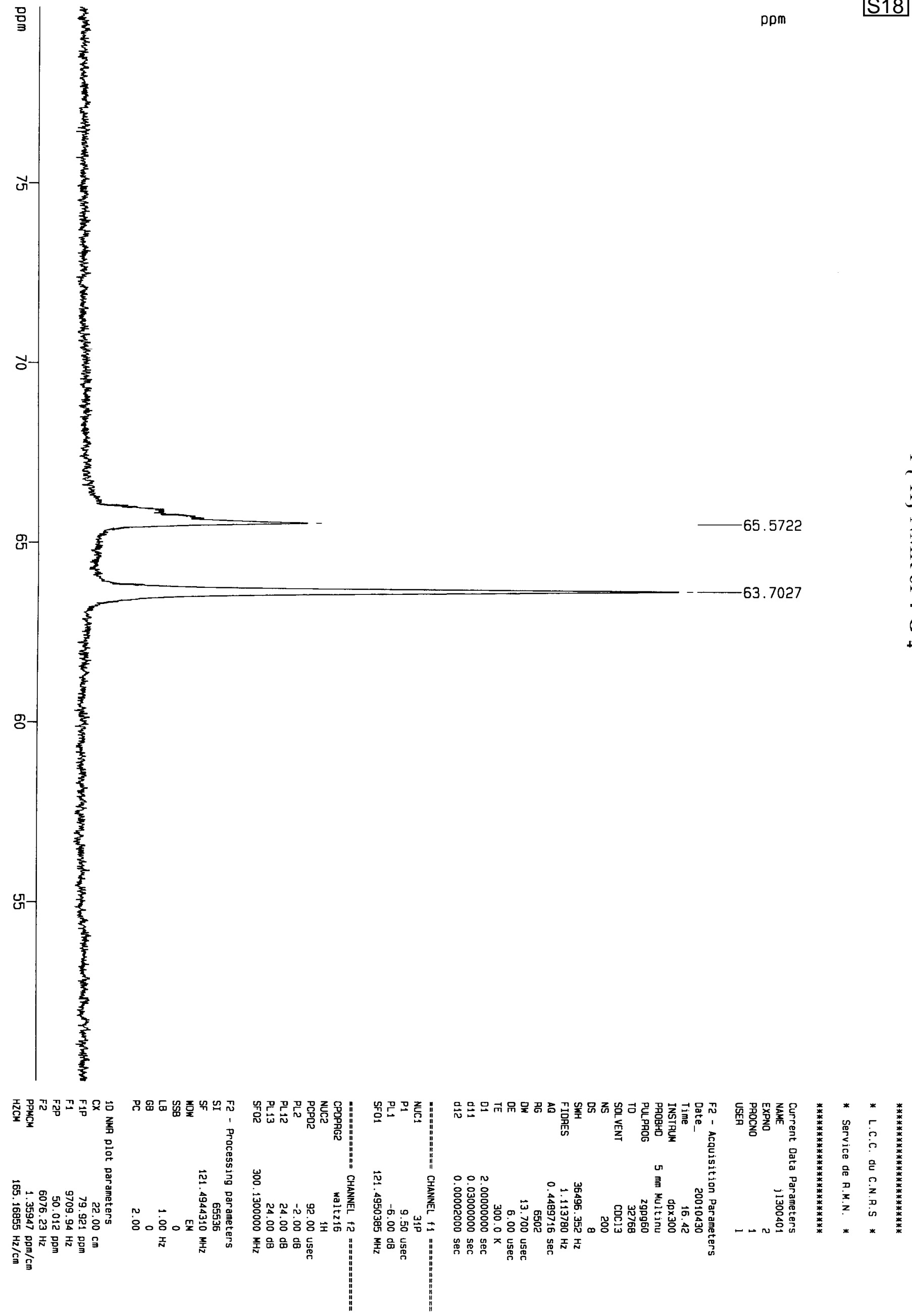


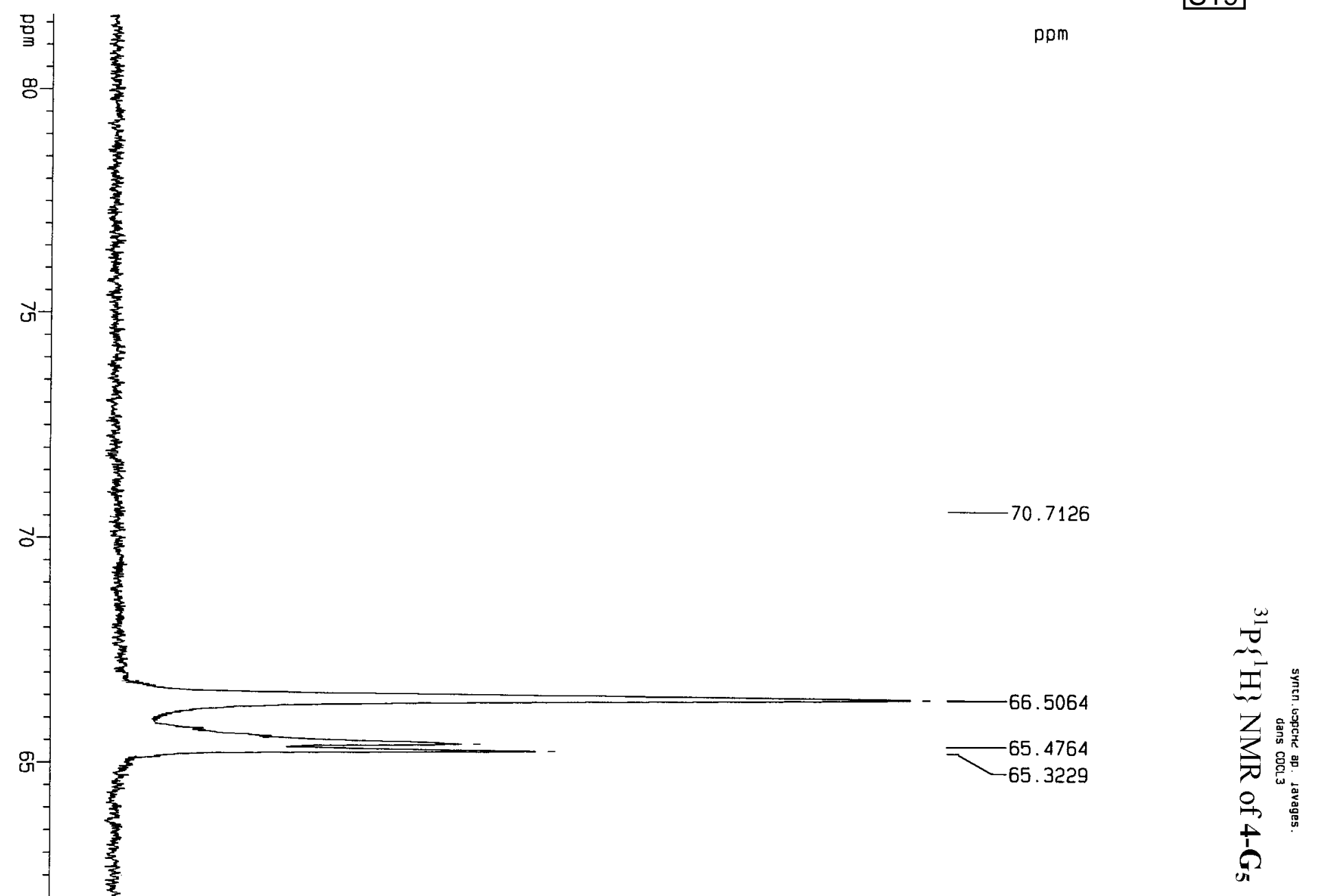

年-

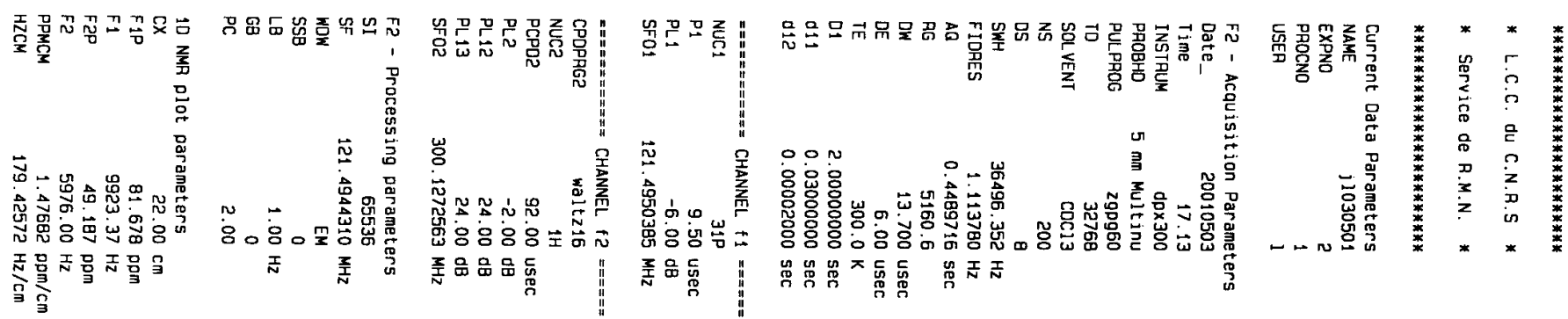




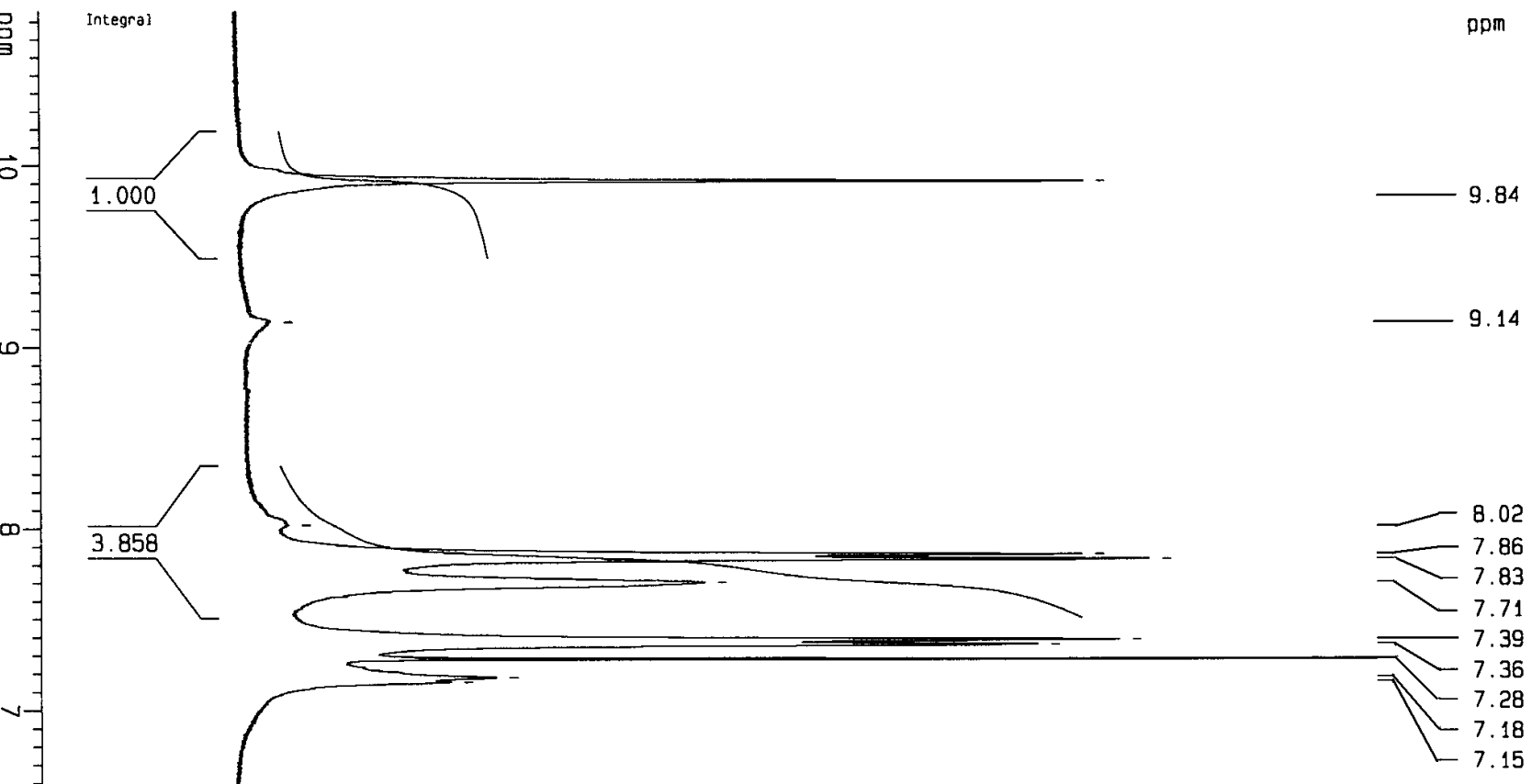

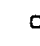

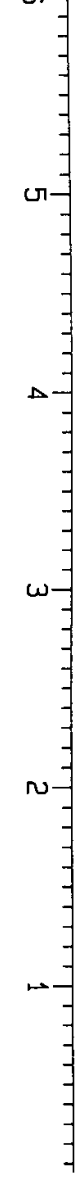
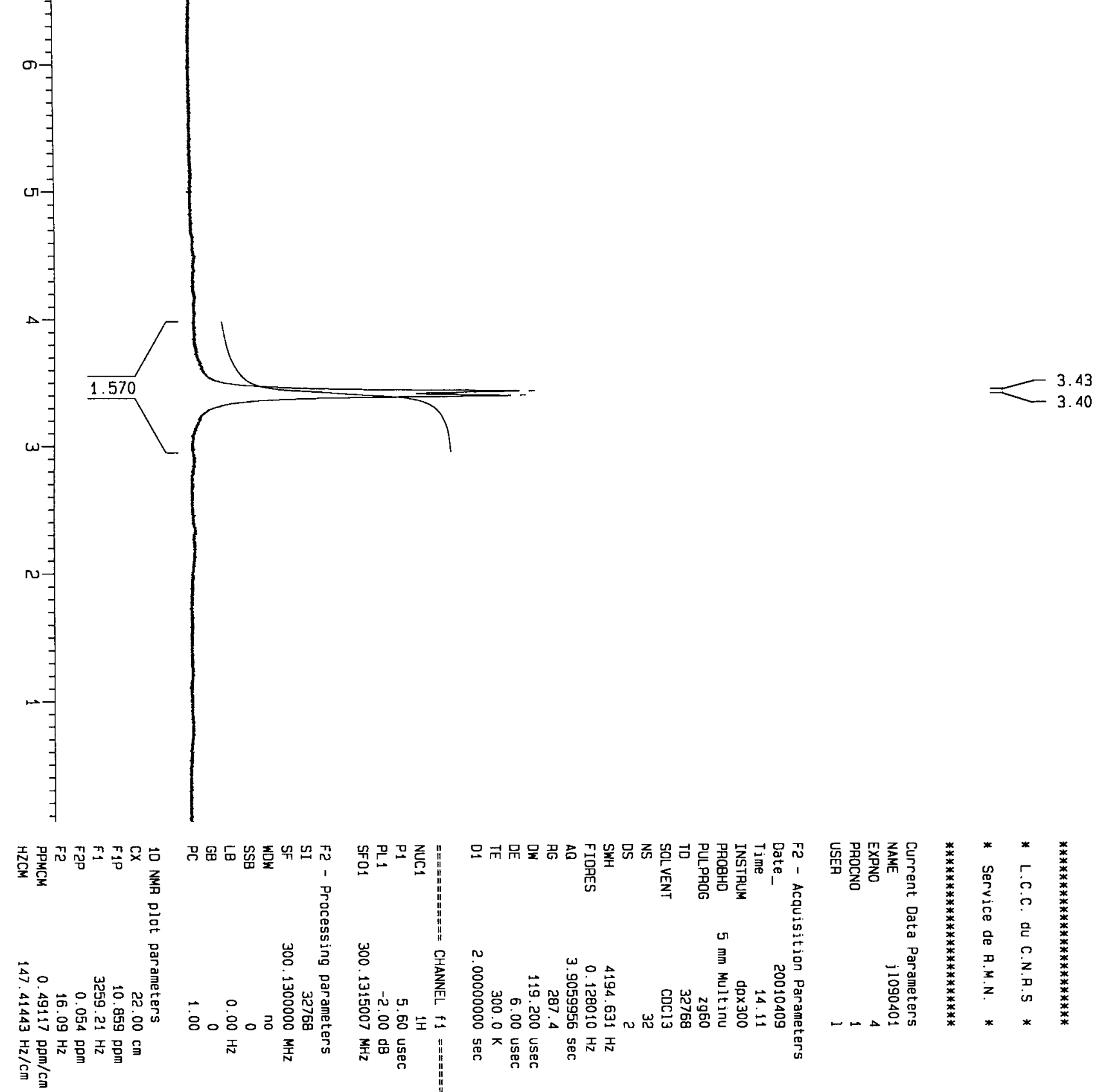

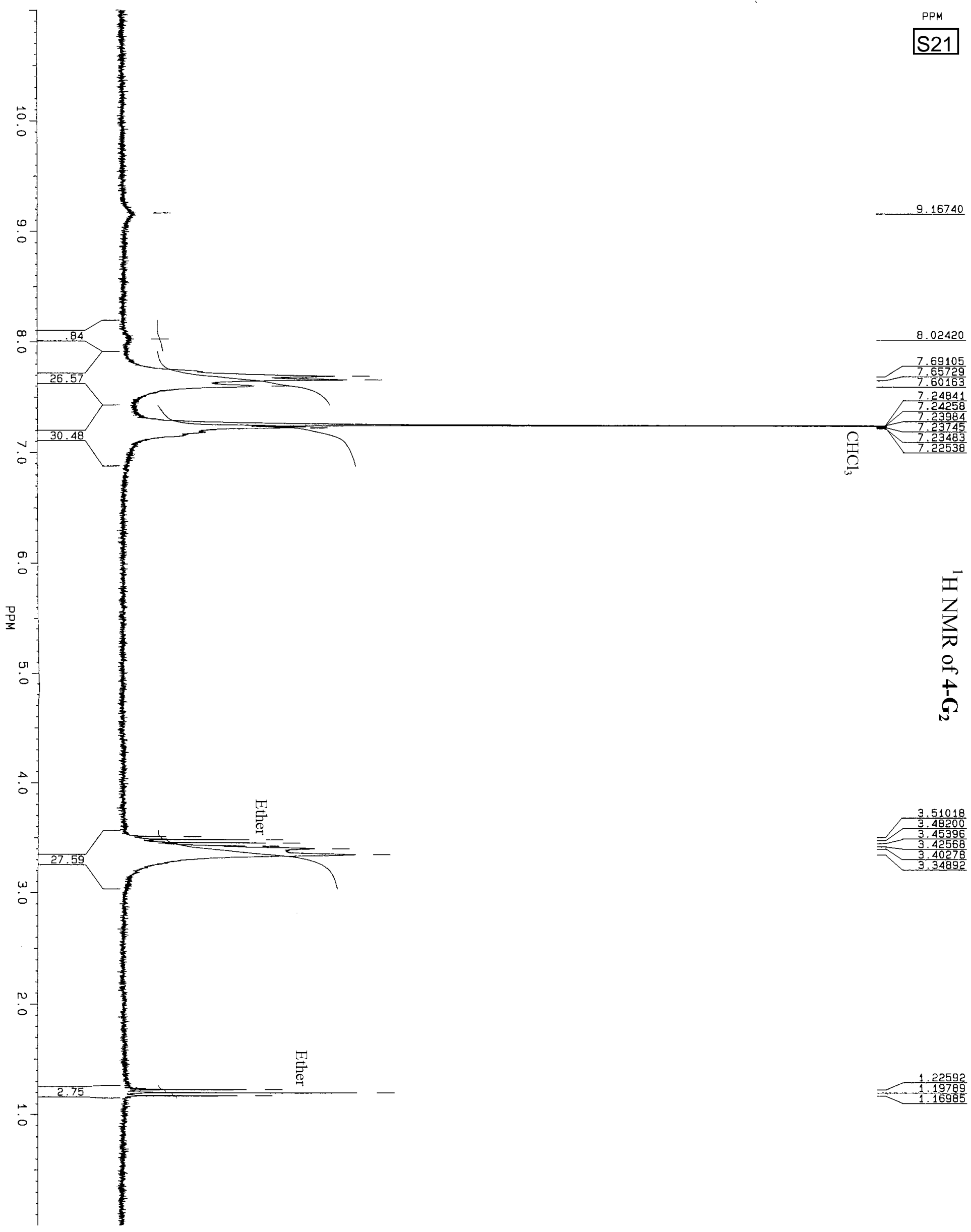

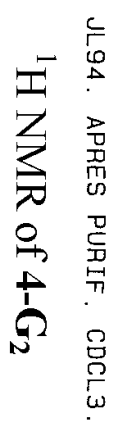

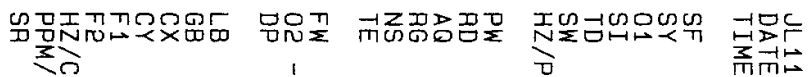
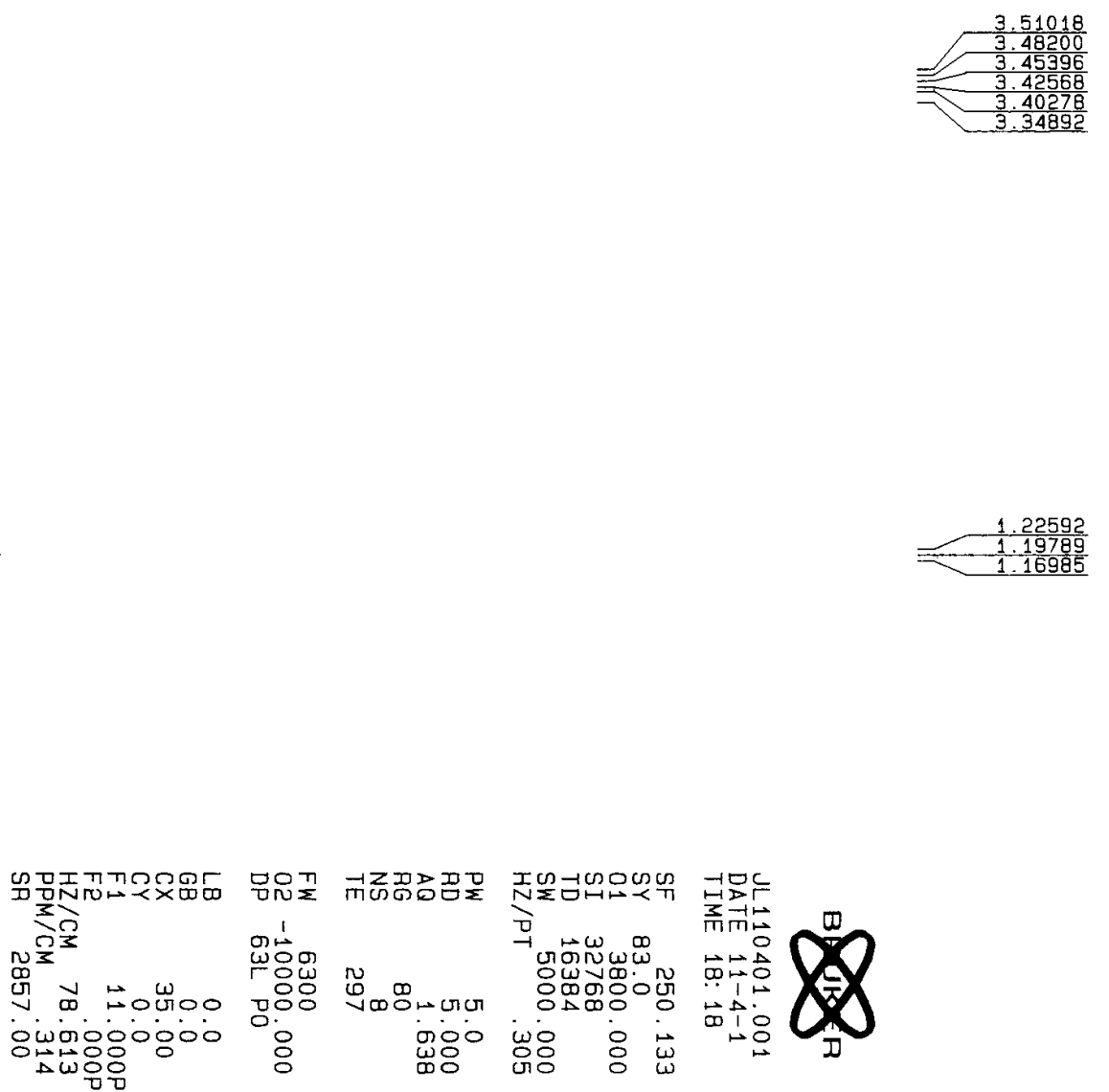

苞 w

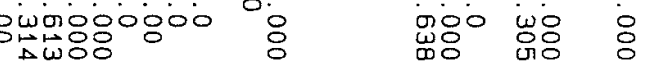




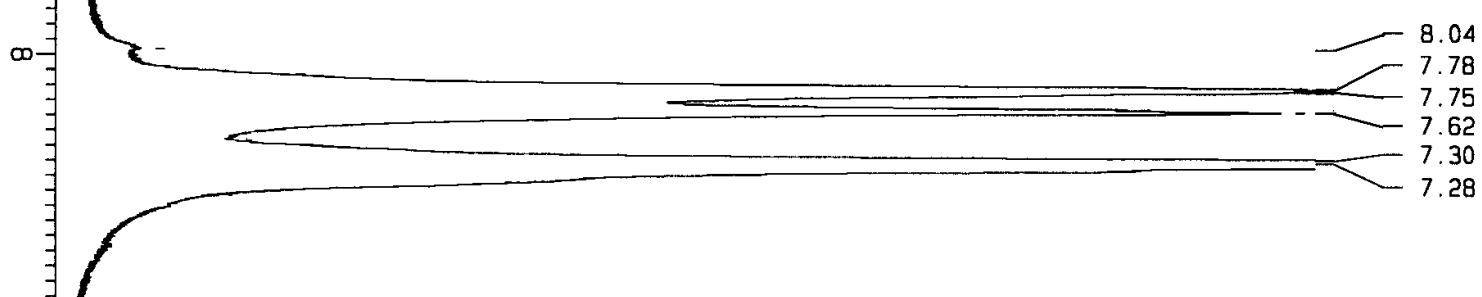

ar

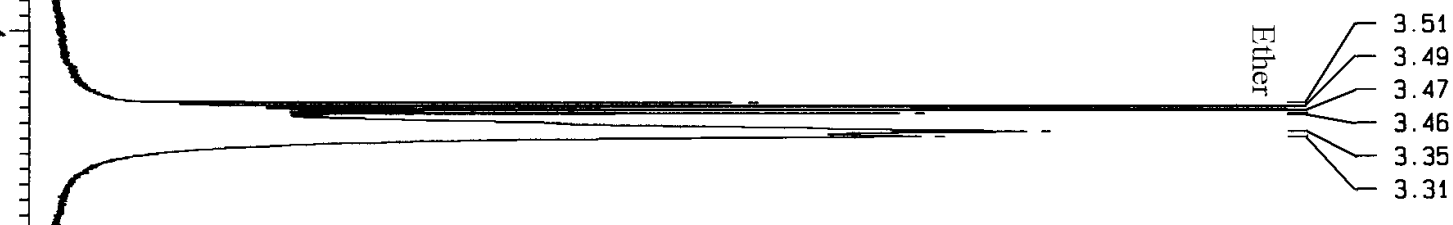

$n=$

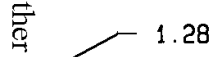

1.25

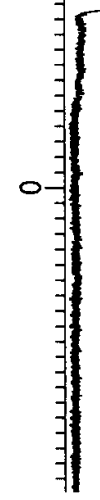

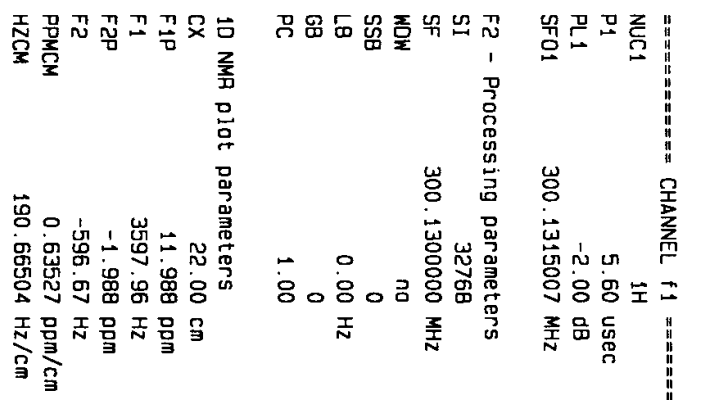

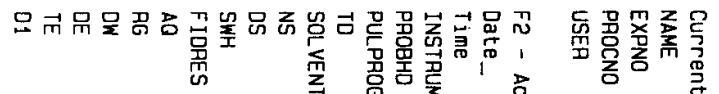

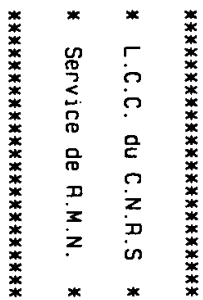



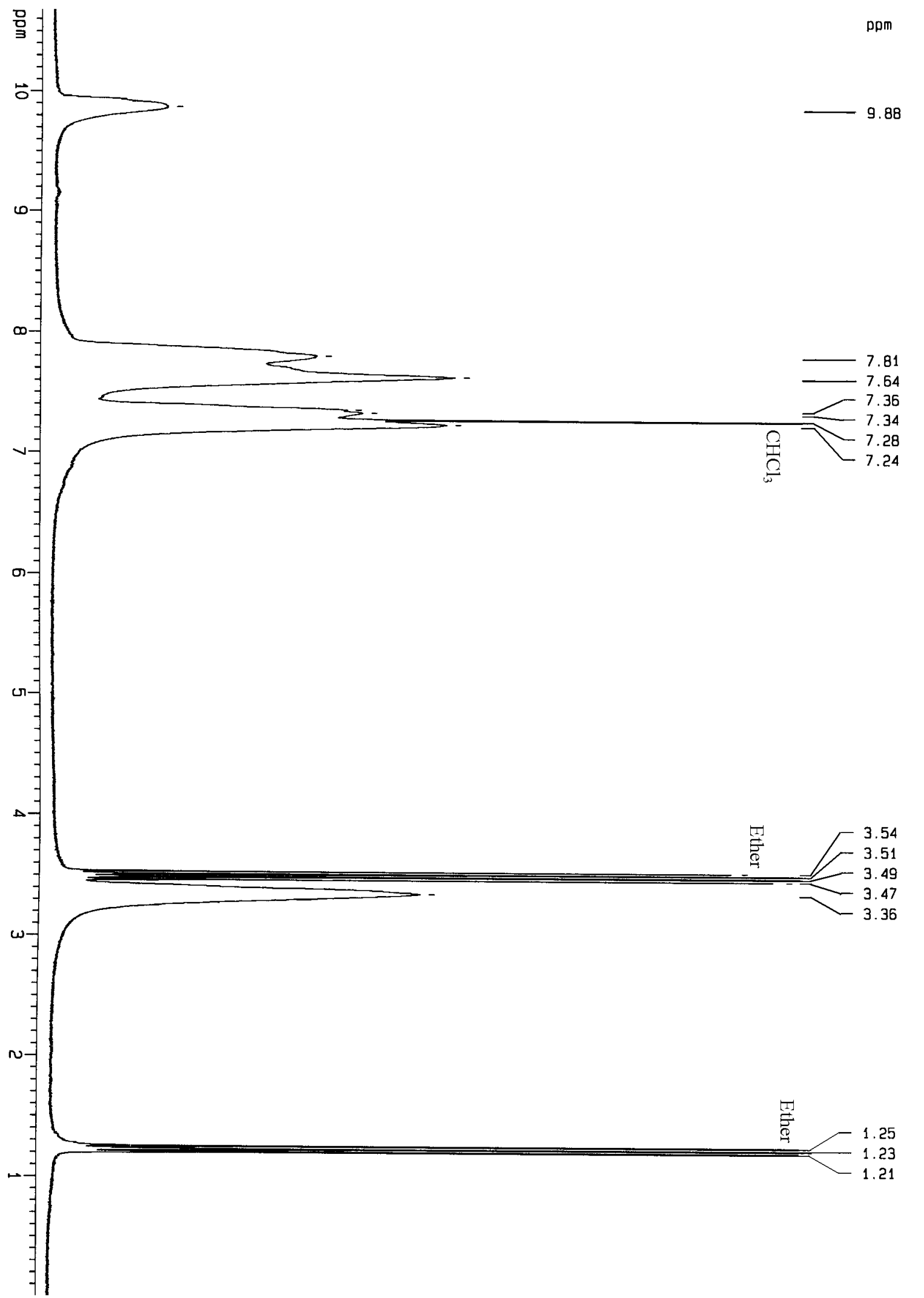

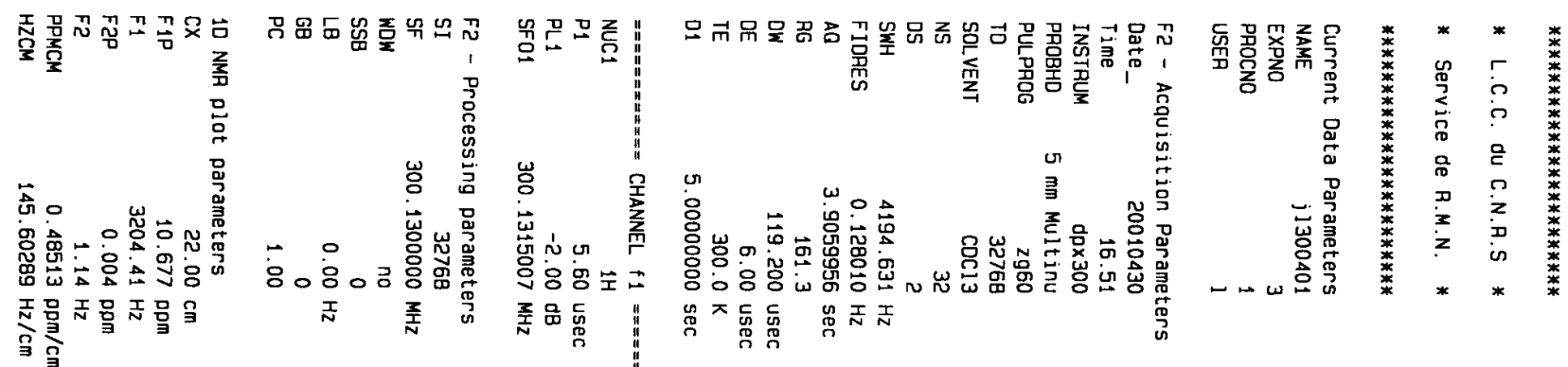



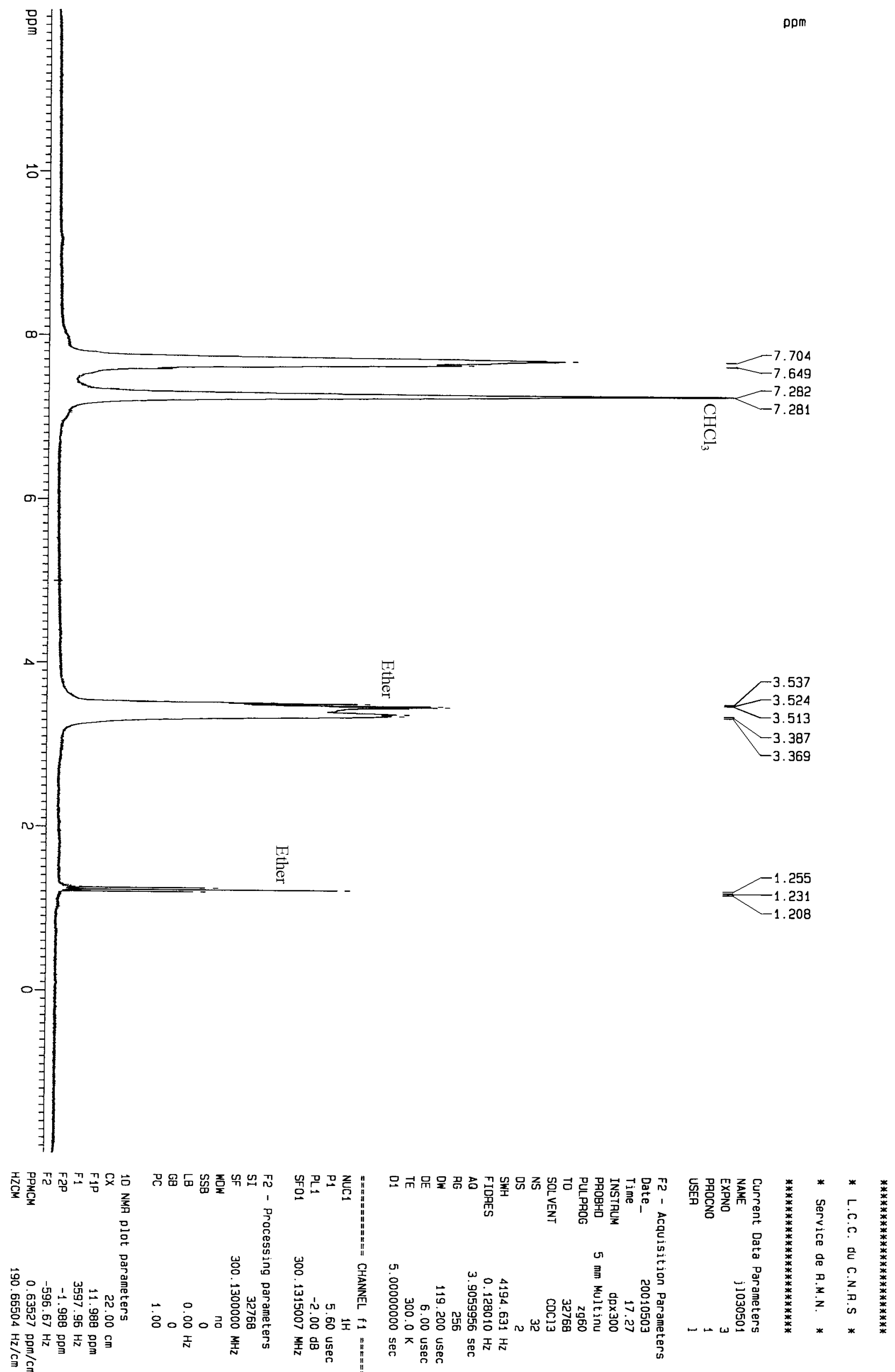

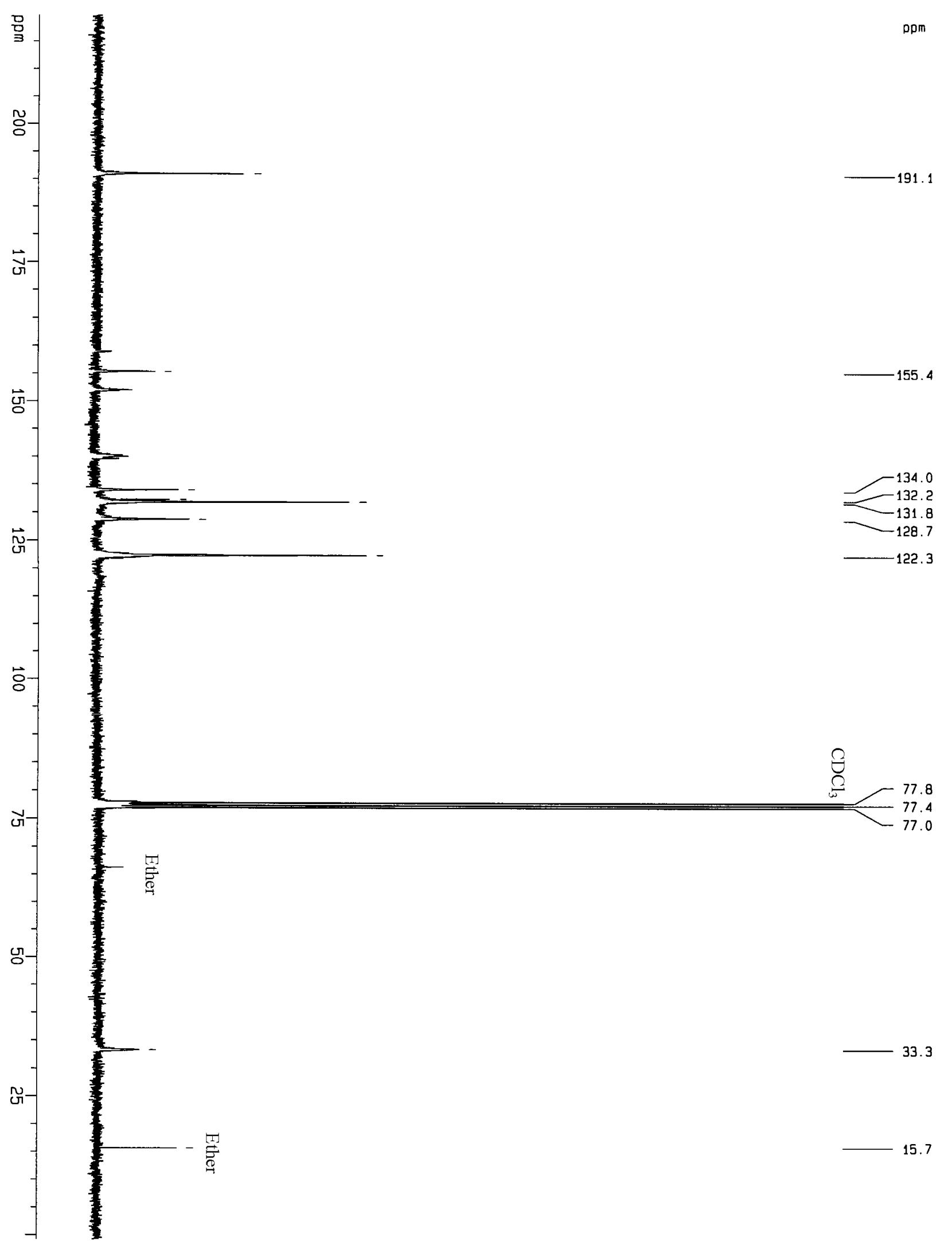

당-

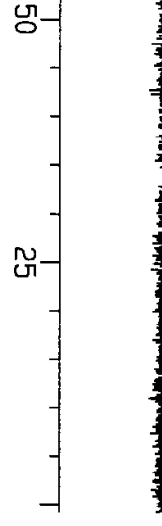

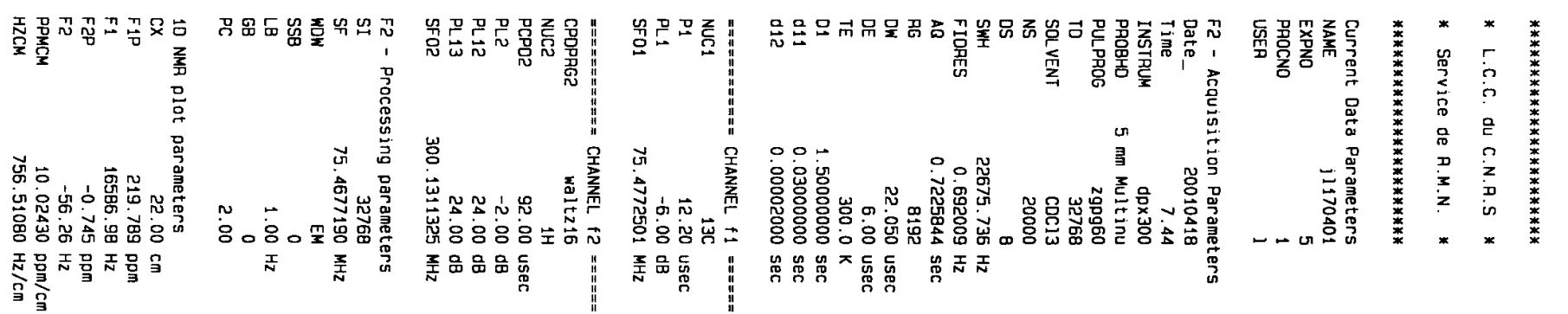

